\title{
SOBRE EL NOMBRE DE LA CIUDAD IBÉRICA Y ROMANA DE VILLAJOYOSA Y LA UBICACIÓN DEL TOPÓNIMO ALONÍS/ALONAI/ALLON
}

\author{
ANTONIO ESPINOSA RUIZ \\ Área Municipal de Arqueología, Etnografía y Museos de Villajoyosa \\ Área de Arqueología, Universidad de Alicante
}

José Miguel Llorca et Juan Segovia, duoviris

\begin{abstract}
Resumen. En este artículo revisamos la argumentación que realizamos hace diez años en nuestra Tesis doctoral sobre la identificación de Alonís/Alonai/Allon con la ciudad ibérica y romana de Villajoyosa, analizando las recientes publicaciones de otros autores en las que se ha abordado esta cuestión y poniéndolo todo a la luz de las nuevas evidencias arqueológicas. El papel de este núcleo como lugar central de la comarca de la Marina Baixa y su relevancia en el contexto de las costas valencianas en las épocas ibérica y romana (en la que llegó a alcanzar el rango de municipium), así como las importantes evidencias arqueológicas monumentales y muebles, hacen improbable que su nombre no se viese reflejado reiteradamente en las fuentes grecolatinas. Del mismo modo, Alonís/Alonai/Allon son topónimos que aparecen en las fuentes clásicas (este último, en varias ocasiones). Analizamos la coherencia con esas fuentes de su reducción a Villajoyosa, que permite casar la ciudad privilegiada sin nombre y el nombre reiterado sin ciudad. Palabras clave. Municipio romano, Allon, Alonis, Villajoyosa
\end{abstract}

\begin{abstract}
Here we review the argumentation we made ten years ago, in our Doctoral Thesis, about the identification of Alonís/Alonai/Allon with the Iberian and Roman city of Villajoyosa, analyzing other authors' recent publications on the same matter and the new archaeological evidences. This site was the main centre in the Marina Baixa region and a quite outstanding one in the Valencian coasts in Iberian and Roman times (reaching the rank of Roman municipium). All this, together with the importance of monuments and finds, makes it unlikely not to find repeatedly its name in Greek and Roman writers and itineraries. In the same way, Alonís/Alonai/Allon are place-names mentioned in ancient texts (the last one several times). We analyze here the coherence of our hypothesis (about identifying those mentioned name-places with Villajoyosa) with those ancient texts. As such, we can couple the privileged unnamed city with the repeated name without a concrete location. Key words. Roman municipium, Allon, Alonis, Villajoyosa
\end{abstract}

En distintas publicaciones anteriores hemos tratado la cuestión de la reducción del topónimo Alonís/Alonai/Allon a la ciudad ibérica y romana de Villajoyosa (Alicante), respectivamente. En nuestra tesis doctoral (Espinosa, 1996a) abordamos ya esta cuestión directamente, acometiendo la argumentación que a nuestro juicio soporta esta hipótesis -ya enunciada anteriormente por otros autores, sin desarrollarla-, y que publicamos en 1998 en un artículo aparecido en la revista de investigación Sarriá (Espinosa, 1998b). La aparición de nuevos datos que apoyan la identificación que proponemos y la publicación en este intervalo de tiempo de algunos trabajos en los que se aborda la cuestión del topónimo, con muy diferentes propuestas, nos anima a exponer aquí los argumentos que hemos defendido reiteradamente con anterioridad, revisando al tiempo el estado actual de la cuestión.
Después de nuestros trabajos de 1996 y 1998, las principales publicaciones recientes que han hecho referencia a la ubicación de Alonís, Alonai y Allon son los de Josep Corell (1999) y Pierre Moret (2000), y encontramos referencias en otros de Antonio García Menárguez (2001), Guillermo Morote (2002) y Géza Alföldy $(2003)^{1}$. En

1. Y no faltan menciones recientes incluso en la prensa: véase por ejemplo el artículo de David Garrido en el Diario Información, edición de Elche, 21-08-2006, página i16, titulado «La antigua Alonis». En el contexto costero provincial, las diferentes ciudades que se identifican con este antiguo topónimo cuentan con todo tipo de entidades y firmas con este nombre: desde el equipo de fútbol Alone Guardamar a los hoteles Alone de Finestrat y de Benidorm o los Apartamentos Alonís de esta última ciudad, pasando por numerosos restaurantes y empresas de todo tipo, particularmente en Guardamar, Santa Pola y el área Villajoyosa-Benidorm, precisamente las que se disputan la reducción del topónimo antiguo. 


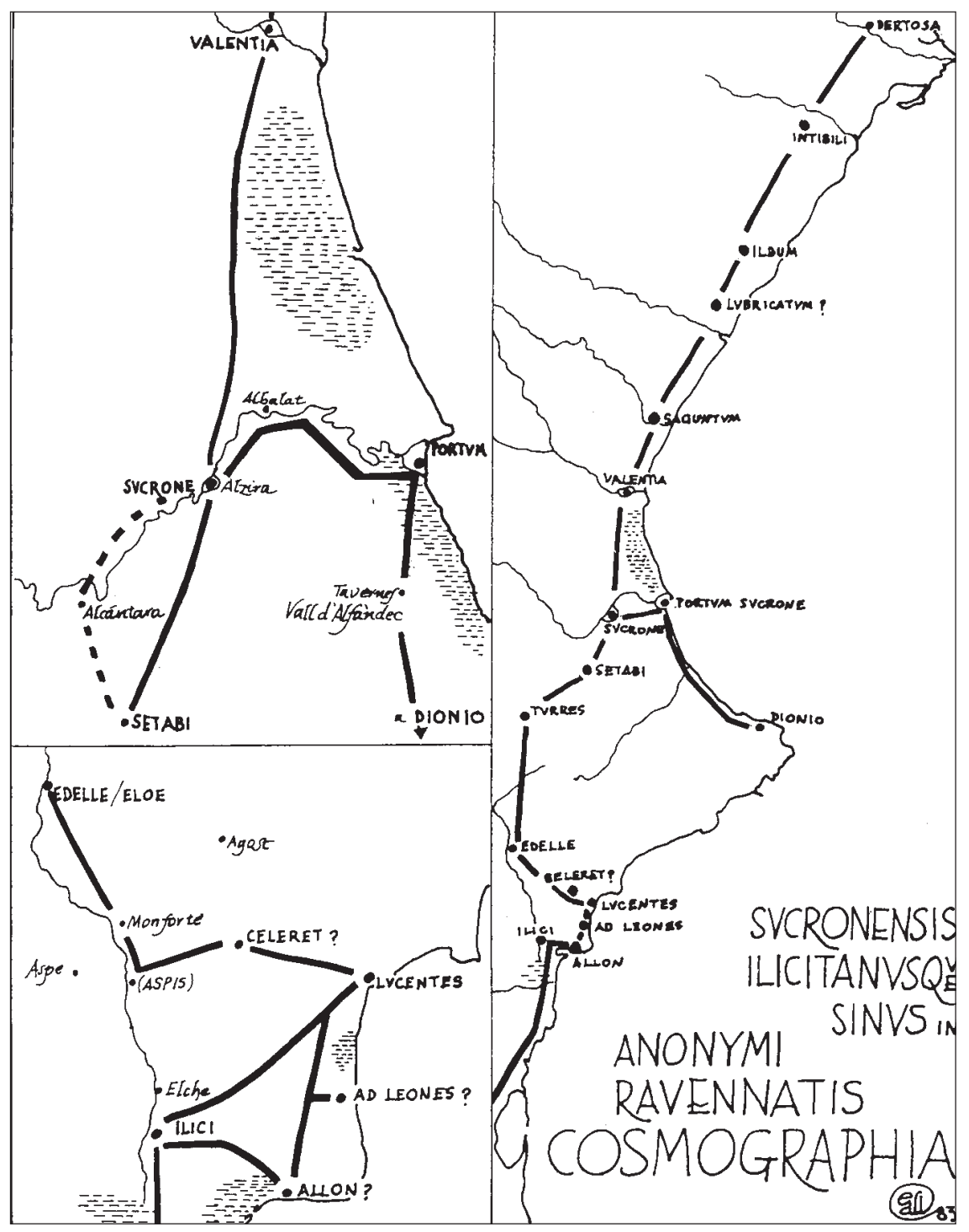

Figura 1: las vías romanas en el País Valenciano, según E. A. Llobregat (1983).

todos ellos (particularmente en Espinosa, 1996 y 1998b; Corell, 1999, Moret, 2000 y Morote, 2002), se hace una completa revisión de la historiografía anterior y se recogen un buen cúmulo de datos y de prolijas interpretaciones que huelga detallar aquí, por lo que remitimos al lector a los mismos. La publicación casi simultánea de los trabajos de Corell (1999) y de Moret (2000) es la causa de que ninguno de los dos analice los argumentos y las conclusiones del otro, emanados por otra parte de diferentes puntos de vista: el de la epigrafía latina y el de de la investigación de las culturas ibérica y griega. Intentaremos, por tanto, abordar una síntesis que no es en absoluto fácil, porque los distintos autores han realizado un magnífico esfuerzo interpretativo, basado en argumentos arqueológicos, filológicos y geográficos.
Sin duda el asunto merece exprimir las fuentes hasta donde sea posible, hacer un esfuerzo contextualizador de las mismas, cotejarlas con la realidad arqueológica que conocemos y ponerlo todo junto en activa y en pasiva. Tampoco es menos cierto, creemos, que las fuentes tienen un límite, y el estado de nuestros conocimientos arqueológicos también, aunque en este segundo caso ese margen avanza constantemente, y en los últimos tiempos a velocidad considerable, arrojando nueva luz a la que contemplar los textos: de ahí que el tema que abordamos esté en el candelero ahora más que nunca.

El asunto lo merece, decimos, porque Alonís/Alonai/Allon parece tener algunas claves importantes para la arqueología protohistórica y clásica del Mediterráneo occidental y, por tanto, 
la cuestión no reviste una importancia secundaria, relativa o de alcance meramente regional. Para empezar, Alonai es un enclave antiguo, mencionado por Artemidoro de Éfeso hacia 100 a. C. como «isla y ciudad de Massalia», es decir, como una población griega, lo que retrotraería su problemática al menos al s. V a. C. y justifica el revuelo científico y los ríos de tinta que se han vertido sobre su verdadera entidad y su localización.

Alonís es, probablemente, una de las «tres fundaciones de massaliotas»" de las cuales "la más conocida es Hemeroskopeion», a las que alude en el s. I a. C. otro geógrafo griego, Estrabón (III, 4, 6), quien afirma que están situadas entre el Júcar y Cartagena, «no lejos de dicho río»-lo que, dicho sea de paso, parece cuadrar mejor con Villajoyosa que con Santa Pola, otra de las principales candidatas, bastante más alejada del Júcar-.

Todo ello ha provocado, lógicamente, distintos posicionamientos al respecto de no pocos investigadores, desde la aceptación sin más de éste y otros posibles asentamientos coloniales al oeste de Emporion y Rhode hasta la negación de su existencia, pasando por soluciones de compromiso, que actualmente parecen mayoritarias, y que aceptan la posibilidad de barrios portuarios helénicos en enclaves indígenas (sobre esta cuestión vid. Moret, 2000, 249-250). Todo ello se enmarca en cuestiones generales que reclaman atención, como la intensa helenización de la cultura ibérica desde el s. V a. C. (particularmente en la Contestania, entre el Júcar y Cartagena); la fuerte relación comercial entre los gymnetes -más tarde Contestanos- y los enclaves griegos del Golfo de León y, en relación con ello, la aparición de los sistemas de escritura ibéricos, etc. P. Moret $(2000,249)$ opina, precisamente, basándose en el análisis de las fuentes, que «malgré la mention d'un lien avec Marseille, Alônis n'est pas expressement désignée comme une fondation coloniale».

Por otra parte, Allon es también un enclave reiterado en las fuentes romanas imperiales: se trata, sin duda, de un lugar recurrente y destacado en nuestra geografía antigua, y no puede ser reducido, de entrada, a un enclave secundario, o de limitada duración temporal.

En nuestra opinión (como argumentaremos a continuación) ambos topónimos, Alo-

2. Como veremos, P. Moret $(2000,254$, argumentado a lo largo de las páginas anteriores) cree que no es probable que Alonis tenga algo que ver con las tres pequeñas poblaciones massaliotas a las que alude Estrabón. nís (probablemente la forma helenizada de un nombre de ciudad indígena, algo común en los geógrafos griegos) y Allon, hacen referencia a un mismo núcleo urbano, primero ibérico, más tarde romanizado (hasta el punto de alcanzar la categoría de municipium hacia 74 d.C. con la Lex Flavia Municipalis).

En palabras de E. Llobregat (1983, 238) «ciudad más removida por los autores que ésta (en referencia a Allon/Alonai/Alonís), y de la que se haya hecho mayor número de reducciones, no la hay en toda la geografía alicantina». De hecho, la identificación geográfica de este topónimo es una de las grandes incógnitas históricas de la arqueología valenciana, con implicaciones importantes para la arqueología peninsular.

Hasta 1983, cuando Enrique Llobregat acometió por primera vez la elaboración de una hipótesis argumentada sobre esta cuestión, las distintas propuestas habían sido tan numerosas como variopintas ${ }^{3} \mathrm{y}$, en mayor o menor grado, meramente enunciativas. Esta falta de argumentación anterior, y la relativa escasez u oscuridad de los datos arqueológicos, no propiciaba que se suscitara una auténtica polémica científica, como la actual.

En nuestra Tesis doctoral (1996) pretendimos analizar la argumentación de Llobregat, que ubicaba estos topónimos en Santa Pola, y cotejarla con la realidad arqueológica que, ya entonces, transcurridos casi tres lustros, apuntaba importantes novedades, elaborando una hipótesis basada en una revisión completa de las fuentes antiguas y las publicaciones recientes, así como de los nuevos hallazgos arqueológicos en Villajoyosa. Intentamos entonces apoyar esa hipótesis en una nueva argumentación que combinara todos esos datos, yendo más allá de simples opiniones o juicios a favor de la ubicación de Alonís, Alonai y Allon aquí o allá.

Hoy, diez años después, esas novedades se han multiplicado incesantemente, y nos encontramos en un punto crucial, en el que están saliendo a la luz, por primera vez, espacios monumentales que podemos adscribir a la ciudad romana. Este artículo tiene, pues, un cierto aire de caducidad prematura, puesto que no es descabellado aspirar a disponer, más pronto que tarde -al actual ritmo de investigación de campo-, de un epígrafe en el que se mencione el ansiado nombre antiguo de Villajoyosa. No obstante, hemos creído necesario, como decimos, desem-

3. P. Moret (2000, 242, nota 23 ) hace una revisión de las diferentes ubicaciones que se han propuesto para Alonís. 


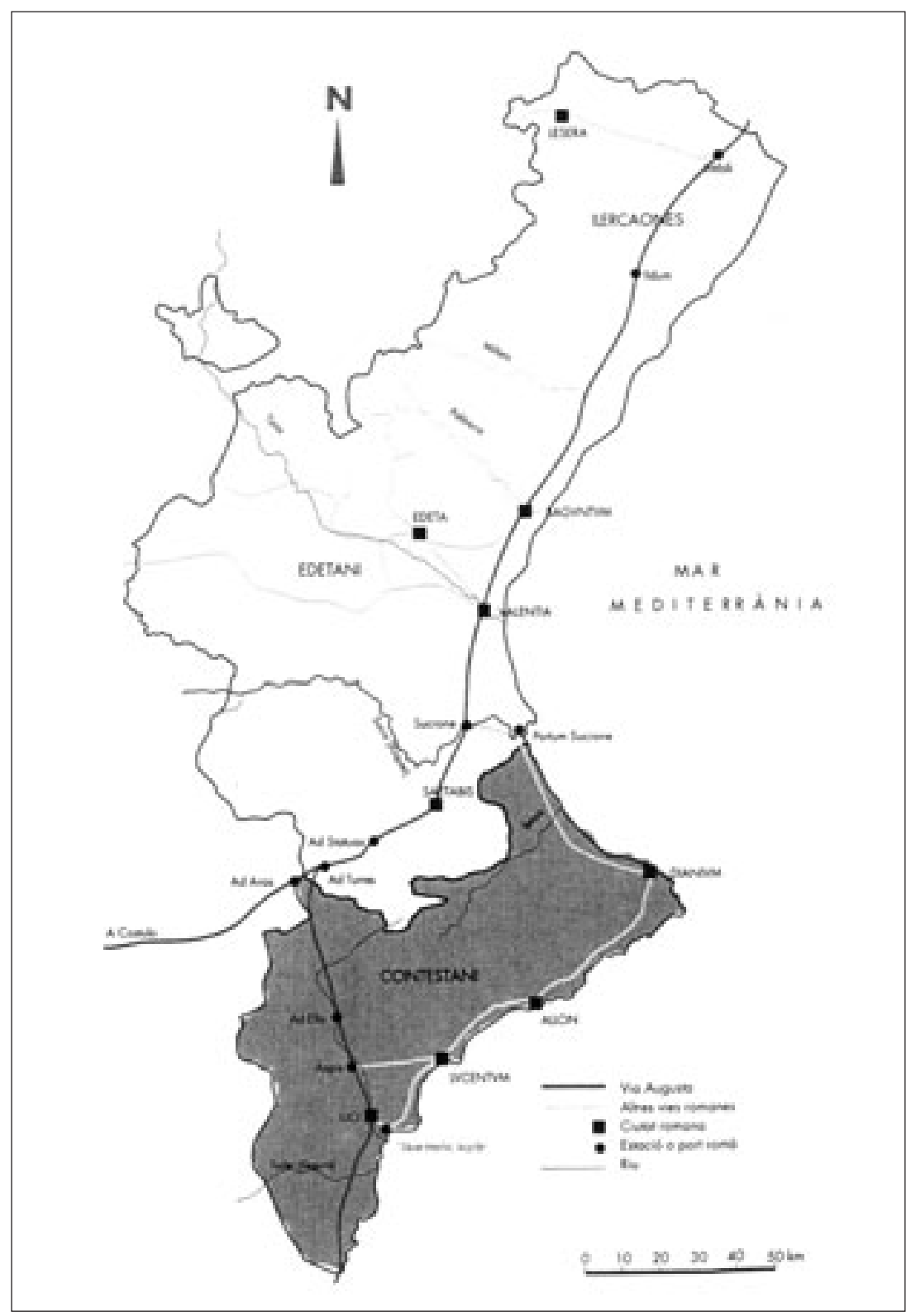

Figura 2: las vías romanas en el País Valenciano, según J. Corell (1999, 401, mapa 1).

polvar el trabajo que realizamos en la tesis, la hipótesis que allí expusimos y su argumentación a favor de la equivalencia Alonís=Allon y su identificación con el núcleo ibérico y romano de Villajoyosa, revisándola a la luz de las posteriores fuentes bibliográficas y arqueológicas.

\section{EL NOMBRE DE LA CIUDAD ROMANA DE VILLAJOYOSA: CINCO SIGLOS DE DEBATE.}

Las propuestas sobre el nombre de la ciudad romana de Villajoyosa han sido variadas a lo largo de la historia, y no han estado exentas de argumentos filológicos sin contraste arqueológico (cf. Espinosa, 1998b). El emblema del pasado romano de la comarca era una construcción que había permanecido siempre visible: la Torre de Sant Josep, en la partida de Torres de Villajoyosa. Se trata de un monumento funerario turriforme (el mejor conservado del País Valenciano) de edícula cerrada, situado a unos $3 \mathrm{Km}$. al $\mathrm{E}$ del casco urbano y a $120 \mathrm{~m}$. de la playa del Torres (Fig. 6), redescubierto y estudiado por Lorenzo Abad y Manuel Bendala (1985). Eruditos y cronistas quisieron pronto relacionarlo con una importante ciudad, que conjeturaban ubicada en los alrededores. 
Pedro Antonio Beuter (1538, I. I, cap. 13) propuso que los griegos de la Jonia, en época colonial, fundaron una urbe a la que, en rememoración de su origen, llamaron Jona. Esta palabra habría degenerado y se habría convertido, sucesivamente, en Jonosa y Joiosa. El nombre de la torre antes mencionada parecía cuadrar perfectamente. Esta hipótesis caló en la erudición local, que aceptó el gentilicio jonense, carente de la más mínima base histórica, aunque actualmente consagrado por el uso.

No menos arbitraria, incluso pintoresca, resulta la interpretación de Rafael Martí de Viciana (1566, I. 3, 411): «El nombre de Villajoyosa fué tomado de villa de choças, porque los primeros fundadores della fueron ciertos pescadores, que hallaron en aquel paraje hauer muy grande y cierta pesquera: y comenzaron de hazer choças».

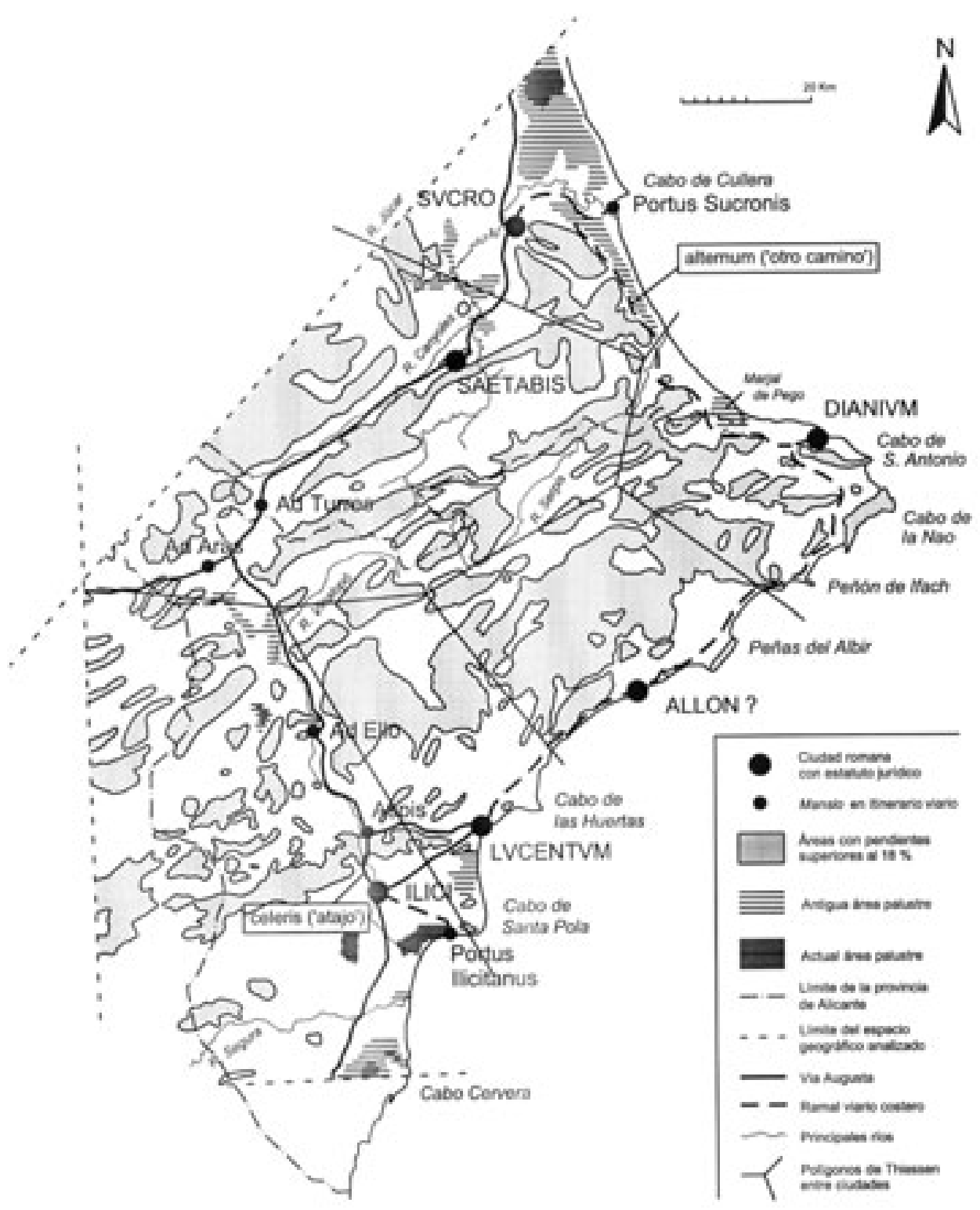

Figura 3: las vías romanas en las comarcas meridionales del País Valenciano, según la propuesta que presentamos en este trabajo, basada en la interpretación de A. Poveda $(1991,69)$ para Celeris y en la de Llobregat $(1983 b, 238-239)$ reinterpretada por Arasa y Rosselló (1995), para Alterum/Alternum/Asterum. Entre las ciudades con categoría jurídica (municipia y coloniae) se han trazado polígonos de Thiessen, que a grandes rasgos coinciden con límites de comarcas naturales o agrupaciones de varias de ellas, que deben corresponder con los territoria de estas ciudades. Basado en Espinosa Ruiz 1996a, fig. 2. Elaborado directamente a partir del Mapa Topográfico Nacional del Instituto Geográfico Nacional, escala 1:50.000. Se han calculado y reflejado las zonas con pendientes superiores al $18 \%$, por la dificultad que suponen para las comunicaciones por tierra. Tambien hemos reflejado las principales áreas palustres, basándonos en el trabajo de Box Amorós (1987), salvo para la de la desembocadura del Segura (vid. Barrier, Montenat y Rouillard, 2004). 
El cronista Gaspar Escolano (1610), que admitía la propuesta de Beuter, fue más allá, siguiendo a otros autores -como el humanista Juan Lorenzo Palmireno-, al tiempo que se basaba en argumentos filológicos: de Jonosa derivaría una tal Honosca que había que situar en el paraje antes mencionado. En realidad Honosca es una mala lectura de Onusa, población litoral citada por Tito Livio (XXII, 20, 3), cuya localización nos es todavía desconocida (aunque parece claro que ha de situarse entre Cartagena y Sagunto)

Fue también G. Escolano (1610 -1879vol. 2, 40-41 $)^{4}$ quien dio la primera noticia sobre un hallazgo excepcional, que había tenido lugar sesenta y siete años atrás: la mensa de un macellum con una inscripción frontal conmemorativa de su reconstrucción (CIL II, 3570), un ejemplar único en el contexto de la epigrafía hispana ${ }^{5}$ (Rabanal y Abascal, 1985, 116-117, n 62; Corell, $\left.1999,185-186, n^{\circ} 106\right)$, que supone una prueba destacada de la existencia de un núcleo urbano en época romana en Villajoyosa. De hecho, un edificio de esta importancia debía localizarse en el centro de esa ciudad (Alföldy, 2003, 49). Los

4. He aquí el texto: «Hechos los romanos señores pacíficos de todo este paraje, volvieron á reedificar á Josa ó Jonosa como parece por las piedras y fábricas que de su tiempo nos han quedado: mayormente por una torre que en el sitio viejo desta poblacion se tiene aun en pié, pero muy arruinada, á quien los nuestros llaman corrompidamente la torre de José, por decir de Josa. Segunda vez en otras guerras pagó la segunda paga al tiempo y fué destruida; y son tantas las piedras que de sus ruinas andan sembradas por aquel suelo, que los navíos que por allí tocan cargan dellas por lastre. En el año mil quinientos cuarenta y tres, cavando los de Villajoyosa en estas ruinas por llevar las piedras para la cerca de la villa que despues se hizo en e sitio que agora la vemos un poco apartado del viejo, descubrieron junto á dicha torre de Josa unos muy grandes y suntuosos sepulcros, de los cuales como de una oficina de cantero sacaron la que hubieron menester cortada ya y labrada. A vueltas destas se llevaron una muy ancha y larga, con un letrero famoso: la cual pusieron en el altar mayor de su iglesia, y dice: M. SEMPRONIUS HYMNUS, ET M. REBURRI EIUS FILII NOMINE SUA M. MARCELLUM VETUSTATE CONLAPSUM PECUNIA RESTITUERUNT ETIAMQUE ET MENSAS LAPIDEAS POSUERUNT. Que quiere decir: Marco Sempronio Hymno en nombre suyo y de su hijo Marco Reburro, restituyó de su dinero la estatua que estaba dedicada al gran cónsul romano Marco MarceIlo, que de vieja se había caido. Y así mismo los dos pusieron delante de dicha estátua ó altar las mesas de piedra».

5. Aunque un fragmento parecido se conserva en Tarraco, como apunta Alföldy, 2003, 49, nota 92). Los macella conocidos hasta hoy en Hispania son muy escasos. A los de Baelo, Bracara, Emporiae y Villajoyosa, mencionados por C. de Ruyt $(1983,267)$, podemos añadir otros como los de Pompaelo y Tarraco (Mezquíriz, 1983, 30-31; Didierjean, Ney y Paillet 1986). vagos datos que proporciona Escolano parecen apuntar a su hallazgo en la partida de Torres, cerca de la Torre de Sant Josep (Espinosa, 1995 y 1996), pero el hallazgo de zanjas modernas para extraer sillares de las termas monumentales en curso de excavación en la C/ Canalejas de Villajoyosa $^{6}$, muy cerca de la muralla renacentista a la que iban seguramente destinados, podría corresponderse perfectamente con la mención de Escolano.

Hubo otras propuestas, como la del historiador Francisco de Diago (1613, t. I, 48-49), que por aquellos mismos años opinó que el nombre antiguo de Villajoyosa fue otro: Etosca, que es una lectura incorrecta de la Osca de Veleyo Patérculo -la actual Huesca-, donde murió el general Quinto Sertorio. De ahí la errónea creencia -extendida todavía hoy entre los vileros-, de que la Torre de Sant Josep es el sepulcro de este general.

Estos intentos de identificar el nombre antiguo de Villajoyosa se relacionan con la necesidad renacentista de clavar en el mapa todos los topónimos disponibles en la literatura griega y romana. Para ello se utilizó el único argumento disponible, el puramente filológico, y se dieron como ciertas simples conjeturas carentes del más mínimo soporte científico, que han arraigado fuertemente en las creencias populares ${ }^{7}$.

La llustración trajo un espíritu nuevo, más racionalista y crítico, que supuso un cambio importante en la actitud con la que los estudiosos se acercaban al conocimiento del pasado. Se buscaba ansiosamente inscripciones en excavaciones o en los muros de los edificios (cf. Mestre Sanchís, 1981). Entre todas las personalidades que dio el s. XVIII nos interesa especialmente Antonio de Valcárcel, Conde de Lumiares, y en particular su principal obra, Inscripciones y Antigüedades del Reino de Valencia, acabada en 1805, pero no publicada hasta cincuenta años

6. Información personal de sus directores, Amanda Marcos y Diego Ruiz, a quienes agradecemos este dato.

7. La anécdota que mejor ilustra este espíritu nos la proporciona, precisamente, la mensa a la que antes aludíamos: efectivamente, una mano anónima, entre 1543 -fecha del hallazgo-y 1610, añadió una «R» por encima de línea a la palabra macellum, que dio pie a Gaspar Escolano (1610, vol. II, 41) para realizar una pintoresca traducción, donde se convertía la mesa del mercado en una inscripción honorífica asociada a una estatua «del gran Cónsul romano Marco Marcello» (nota 4). Evidentemente, la $r$ se añadió con la intención de relacionar el origen de la ciudad con un personaje ilustre. Ejemplos similares de falsificación, con idéntica finalidad, fueron habituales en el Renacimiento. 
más tarde (Valcárcel, 1852 -1979-, 98-101, lám. 59-62).

En Valcárcel encontramos, por primera vez, un interés decidido por aquello que llamamos cultura material, y que, a partir de entonces, dará una nueva luz a los testimonios literarios. De hecho, puede considerársele el primer arqueólogo valenciano.

Fue este autor quien realizó las primeras excavaciones arqueológicas de que tenemos constancia en la comarca. A partir de la vaga referencia que aparece en el texto publicado en 1852, podemos suponer que se desarrollaron (como apuntamos en nuestra Tesis doctoral) en la necrópolis de la partida de Torres: «...entre Cabo Martín y Villajoyosa, en el sitio de las ruinas que se hallan á poco mas de un cuarto de esta última villa, caminando á Denia sobre una pequeña eminencia, 300 pasos distante del mar, la cual paulatinamente se suaviza hasta quedar en llano». Sabemos que «...encontró enteros dos sepulcros con las urnas cinerarias, un baso lacrimatorio y dos medallas de Alejandro Severo colocadas en una pequeña vasija de barro saguntino. Por último manifiesta que los caseríos inmediatos están construidos con piedras conocidamente de fábrica romana, y que se reconoce con bastante claridad los cimientos y recinto de la antigua población» (Valcárcel, 1852 -1979-, 99). En este paraje propuso el autor la situación de las ruinas de una ciudad que identificaba con una tal Idera, lectura incorrecta de un texto de Avieno, que menciona en realidad Ilerda (Ora Maritima, v. 475) ${ }^{8}$.

Durante el s. XIX no encontramos aportaciones sustanciales al conocimiento de la Arqueología romana de Villajoyosa. Ello se inscribe en un contexto general de estancamiento de la investigación sobre la Antigüedad en la provincia, con algunas excepciones que no nos interesan aquí (Abad Casal, 1990, 130). La controversia sobre el nombre antiguo de la ciudad romana -cuya existencia y localización en el término de Villajoyosa se daban ya por supuestas- se ceñía, por una parte, básicamente a los partidarios de Honosca, y por otra a los que se inclinaban por Idera. Sin embargo, ahora se comenzó a contemplar otra posibilidad, anteriormente planteada por A. de Valcárcel, quien posteriormente la rechazó (1852 -1979-, 98-99): la identifica-

8. Llama la atención que, en nuestros días, no se reconozca ese recinto y cimientos de una población antigua, que para Valcárcel eran tan evidentes, en la partida de Torres, donde ni siquiera se detectan en superficie materiales arqueológicos comunes, como los de construcción o la cerámica. ción con Alonís/Allon, defendida más tarde por Aureliano Fernández Guerra y Orbe (1816-1894) en un discurso leído en la Real Academia de la Historia ${ }^{9}$ (Montaner y Simón 1897, 590-591).

Igualmente C. Müller (1883), en su edición de la Geografía de Claudio Ptolomeo, ya propuso la identificación de la Alonai que menciona este tratado con Villajoyosa ${ }^{10}$.

También en esta centuria, la bibliografía comienza a hacerse eco de la importancia arqueológica del área en la que actualmente se asienta la ciudad de Villajoyosa: «Innumerables son los objetos encontrados que demuestran su remota antigüedad y la importancia de su población; en sus alrededores, en una extensión de 3 kms., raro es el día que no se tropiece con algo: monedas, ánforas, estatuas, trozos de columna y toda clase de objetos de cerámica y de vidrio y restos de mosaico (...). En 1896 se encontraron en un campo cercano a la población varios objetos, entre ellos seis pintados, que conserva D. Francisco M. Martínez...» (Montaner y Simón, 1897, 591) ${ }^{11}$.

Como hemos visto, la mayor parte de las teorías tradicionales sobre el nombre de la ciudad antigua de Villajoyosa se basaba en argumentos puramente filológicos, que buscaban una raíz clásica para el nombre actual. Estos argumentos se desvanecen cuando consideramos el hecho de que el nombre de Villajoyosa es del más puro origen romance, y que no es anterior a su creación en torno al año 1300 (Cabanes et alii, 1981, 378-379; Espinosa, 1995a, 24-25). Su

9. Institución de la que este autor fue miembro a partir de 1855.

10. Según G. Morote $(2002,189)$.

11. La mención de Francesc María Martínez i Esquerdo en esta última publicación, entre otras de la época (vid. Figueras Pacheco 1913, pág. 1120), nos da pie para referirnos al incipiente papel de los eruditos locales, algunos de ellos propietarios de interesantes colecciones de antigüedades, y la mayoría prácticamente desconocidos. En el caso de Martínez, tenemos noticia de algunas de sus actividades, como el descubrimiento de una inscripción funeraria en Els Banyets (vid. Rabanal y Abascal, 1985, $60)$, que él creyó un fragmento de miliario, o el de los mosaicos de la importante uilla de Xauxelles, a finales de siglo (Espinosa, 1996 y 1991). Sabemos, además, que ganó unos juegos florales en Alicante, con un libro titulado Historia de Villajoyosa, perdido ya en 1913, según Francisco Figueras Pacheco (1913, nota 948). La extensión de $3 \mathrm{Km}$. alude sin duda a la partida de Torres, hacia el E, y a la villa monumental de Xauxelles, hacia el N, ambas a esta distancia del casco urbano de Villajoyosa. Respecto a la evolución de las investigaciones sobre la Arqueología ibérica y romana en la comarca de la Marina Baixa remitimos a Espinosa, 1998a. 


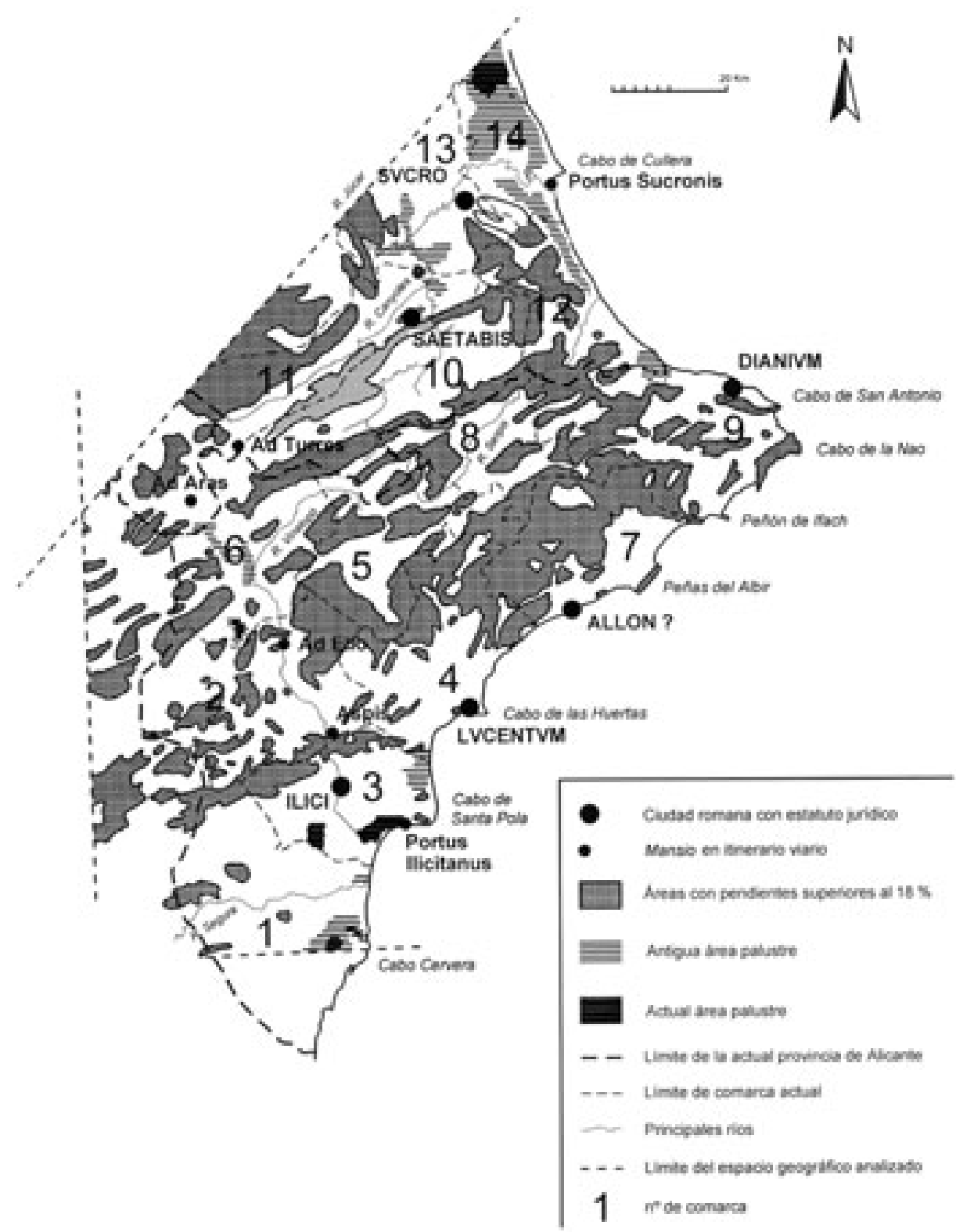

Figura 4: Las comarcas actuales del sur del País Valenciano superpuestas a la geografía romana altoimperial (de Espinosa, Sáez y castillo, 2006). 1, Bajo Segura; 2 Vinalopó Mitjà; 3, Baix Vinalopó; 4, L’Alacantí; 5, L'Alcoià; 6, Alt Vinalopó; 7, Marina Baixa; 8, El Comtat; 9, Marina Alta; 10, La Vall d’Albaida; 11, La Costera; 12, La Safor; 13, La Ribera; 14, La Ribera Baixa.

significado en catalán antiguo es 'ciudad alegre', un nombre adecuado, atractivo, para una vila nova enclavada en la vanguardia del Reino de Valencia, rodeada de enclaves moriscos y que necesitaba urgentemente ser repoblada.

Otros autores han planteado, más recientemente, la identificación de Alonís, Alonai y Allon con Villajoyosa, sin llegar desarrollar una argumentación in extenso: así J. M. Roldán (1975) o M. A. Rabanal $(1985,366)$, quien opina que son probables dos zonas concretas: BenidormVillajoyosa y Alicante-Santa Pola, aunque en otros párrafos parece decantarse más bien por la primera posibilidad (ibíd., 355), e incluso es- pecíficamente por Villajoyosa (ibíd., 364). Varios autores propusieron también la reducción de estos topónimos a Benidorm y su isla ${ }^{12}$; esta teoría se revitalizó con las excavaciones en el poblado ibérico del Tossal de la Cala (Fig. 6) por J. Belda en los años cuarenta y por Tarradell y Ramos en los años cincuenta (cf. Espinosa, 1996) ${ }^{13}$.

12. Un elenco completo en Moret (2000, 243).

13. Sobre la bibliografía relativa a la identificación con Guardamar y con Santa Pola, igualmente vid. Moret (2000, 243). 


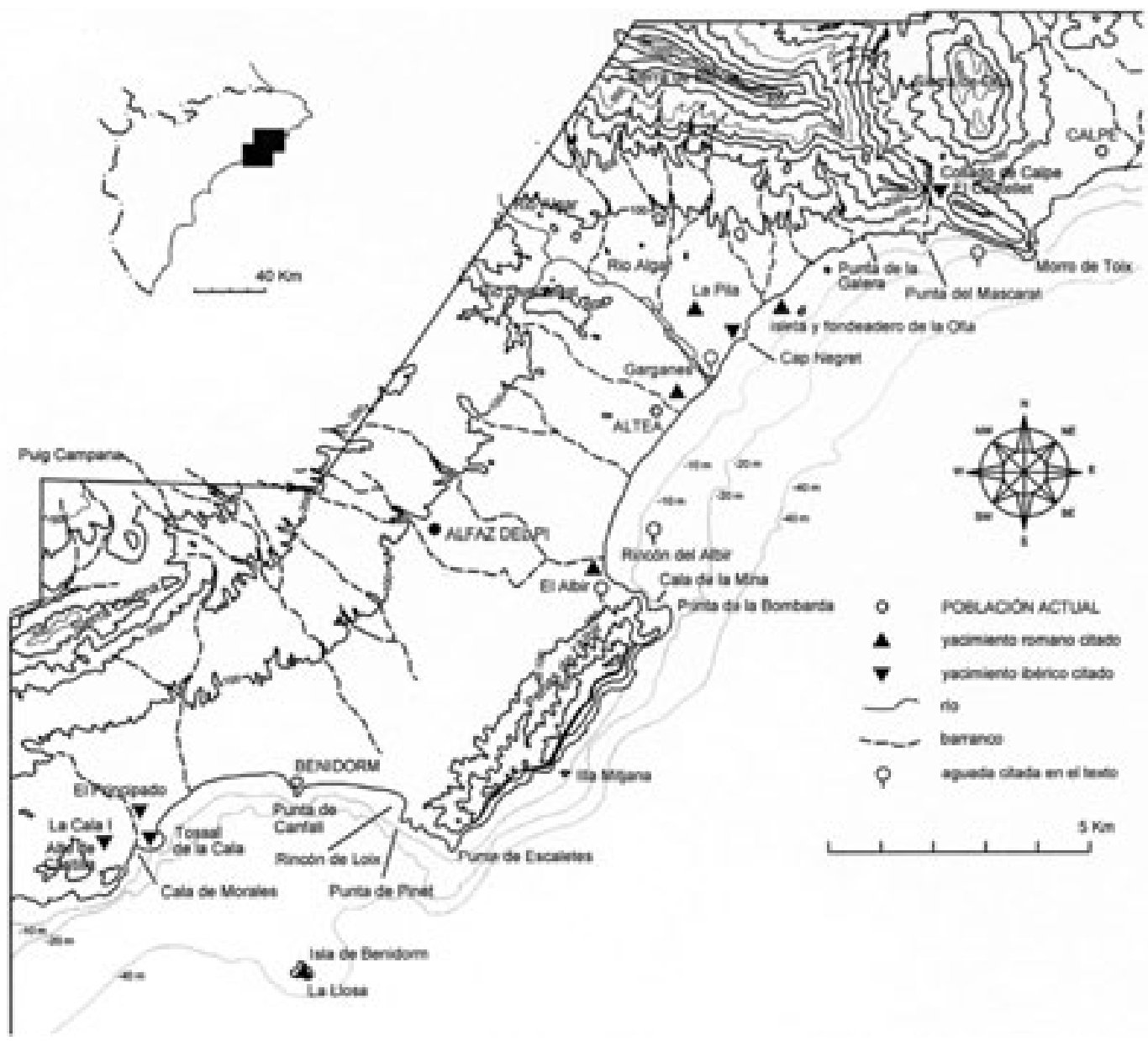

Figura 5: mitad norte de la comarca de la Marina Baixa, con indicación de los yacimientos y lugares mencionados en el texto.

\section{EL MUNICIPIUM ROMANO DE VILLAJOYOSA}

La idea de la existencia de una ciudad romana en Villajoyosa la encontramos ya, como hemos visto, en eruditos renacentistas, pero su identificación con un municipium corresponde a $A$. García Montalbán (1984) y a R. Wiegels (1985, 145-146), basándose en el pedestal dedicado a Q. Manlio Celsino ${ }^{14}$, en el que encontramos el único ejemplo de la tribu Quirina en la provincia de Alicante, y uno de los escasísimos atestiguados en la vertiente mediterránea peninsular. Este dato reafirma la idea de que la ciudad romana de Villajoyosa alcanzó el rango municipal en época

14. Años atrás E. Llobregat $(1974,91)$ dudaba de la existencia de este municipio, basándose en lo que él creyó un carácter funerario de la inscripción dedicada a Manlio Celsino, que abría la posibilidad de que éste hubiera sido duumvir de otra ciudad, y se encontrase en Villajoyosa ya retirado. Sin embargo, la evidencia del carácter honorífico del epígrafe invalida esta hipótesis.
Flavia, como consecuencia del Edicto de Vespasiano, quien otorgó el ius Latii a las ciudades que reunían las condiciones necesarias hacia 73/74 d.C. ${ }^{15}$ (vid. Abascal y Espinosa 1989, 43; Abascal, 1996, 279; Cebrián, 2000, 54). Hay pocas dudas sobre la interpretación de R. Wiegels, porque la Quirina es la única de las 35 tribus romanas en la que inscribieron los Flavios a los nuevos ciudadanos hispanos (McElderry 1918, 78; Montenegro, 1975; Abascal y Espinosa, 1989, 74; Wiegels, 1985, 5).

La primera referencia nos la da B. Ribelles $(1808,573)$, según el cual la inscripción apareció en 1688, y Bayer la vio el 17 de abril de 1782 partida ya en dos fragmentos, en los dos ángulos del corral del Molí de Llinares en el que se conservó hasta su donación en 1978 al Museo de Villajoyosa. Valcárcel (1852-1979-, 100, nn. 334 y 337 ) afirma que su hallazgo se produjo «a

15. Plinius, Nat. Hist. 3,30. Respecto al la fecha exacta en 73/74 o 70/71 vid. Abascal y Espinosa 1989, nota 61. 
media legua de la villa caminando a Denia, en casa de Pedro Linares», donde él mismo pudo observar su mitad superior (ya con la cuarta línea desaparecida), sin asociarla a la inferior, a comienzos del siglo XIX. La indicación topográfica del hallazgo podría sugerir la partida de Torres, pero sin duda se trata de un error de Valcárcel: el Molí de Llinares no se encuentra camino de Denia, hacia el E, sino de Orcheta, hacia el N, y sabemos que los dos fragmentos se encontraban ya en aquel lugar hacia 1760 , según G. Mayans y otras fuentes (vid. Corell, 1999, 183).
No parece lógico, a juzgar por la distribución del poblamiento romano, que este pedestal se encontrase originalmente en el molino de Llinares, ni siquiera en la cercana villa de Xauxelles, 500 $\mathrm{m}$ al sur (Fig. 6). Nos queda, pues, la incógnita de su lugar de hallazgo, que habría arrojado sin duda alguna luz sobre la ubicación del foro de la ciudad romana.

El municipium es considerado como una de las fórmulas más acabadas que Roma creó para su aplicación en las provincias occidentales -esencialmente en las africanas y en las hispa-

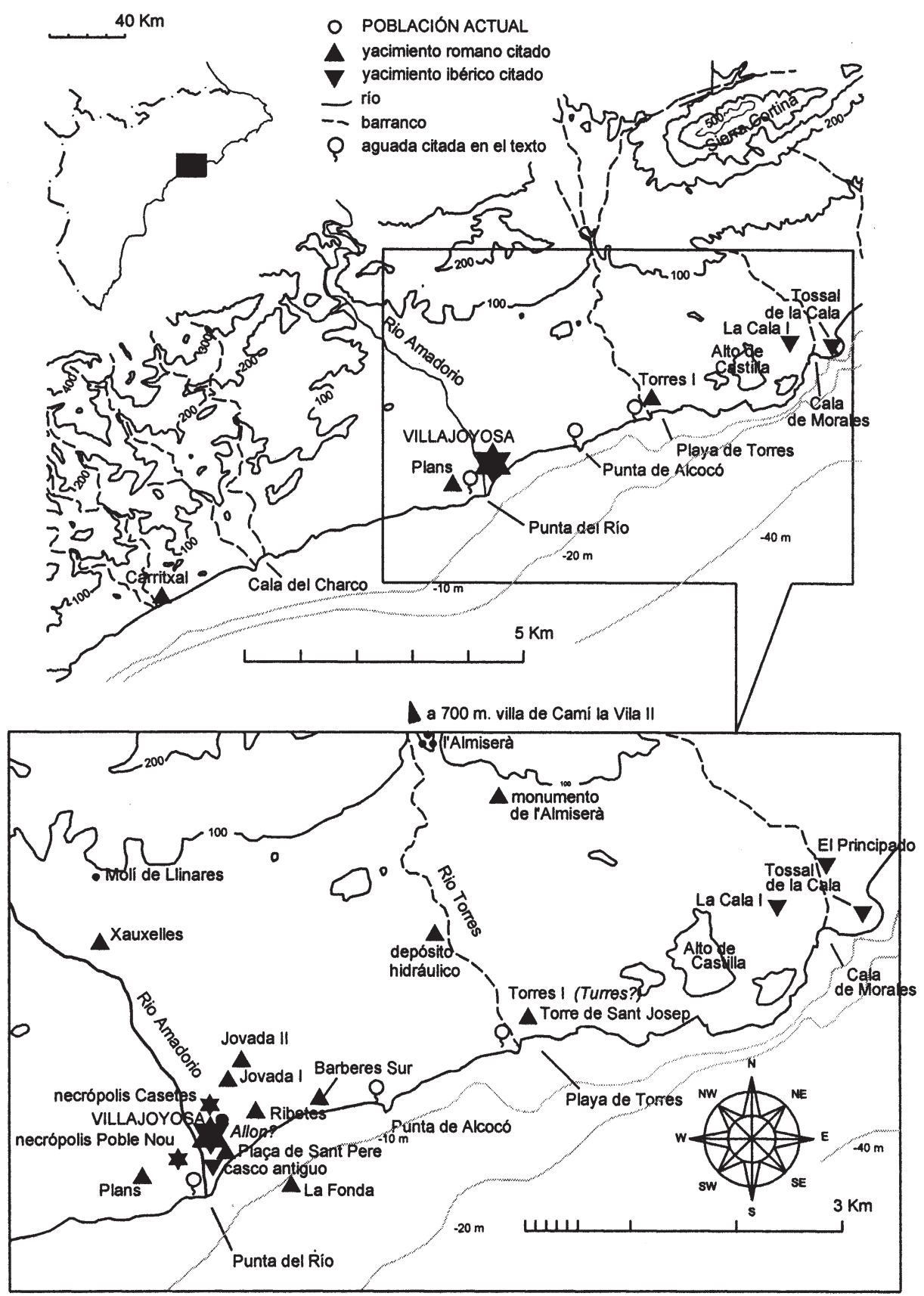

Figura 6: mitad sur de la Marina Baixa, con indicación de los yacimientos y lugares mencionados en el texto. 
nas-. En Lusitania hay yacimientos, poco importantes arqueológicamente, que tienen categoría municipal, mientras que otros, con decenas de inscripciones, esperan eternamente esta consagración, lo que llevó a P. le Roux $(1990,36)$ a afirmar que el estatuto municipal se concedió sin rigor y al azar. Según este autor, tanto en Lusitania como en Hispania algunas ciudades mencionadas como civitas o res publica no han dado pruebas de su rango municipal: nada autorizaría, por tanto, a establecer una relación causa-efecto automática entre ambos fenómenos. La mayor parte de las ciudades de la Galia no tuvieron otro estatuto que el de civitas, y sin embargo poseyeron duoviri, flamines, foro e incluso edificios de espectáculos. En Irni, por ejemplo, había un teatro y un senado local antes de su promoción a municipium en época Flavia. Según este investigador, el hecho de pertenecer a la tribu Quirina no tiene más significado que el cronológico, como prueba de que la ciudadanía fue obtenida con posterioridad al beneficium de Vespasiano, pero no indica necesariamente un municipium, dado que, en una ciudad con derecho latino no municipal, era necesario inscribir también a los nuevos ciudadanos en alguna tribu. Para identificar a un municipium hace falta, según Le Roux, encontrar explícitamente el propio término en la epigrafía (éste no es por el momento nuestro caso). Concluye este autor afirmando que el estatuto de oppidum Latinum constituía por sí mismo un reconocimiento político honorable, y que sin su existencia previa no había municipalización posible (Le Roux, 1990, 40-43).

De cualquier manera, hecha esta puntualización, se puede considerar esencialmenbte correcto utilizar el término municipium para el núcleo de Villajoyosa (vid. Espinosa, 1996, 735736). La arqueología y la epigrafía demuestran que se trata de una población privilegiada en el contexto regional (a la altura de las vecinas Dianium o Lucentum), con magistrados (conocemos un duumvir que fue también flamen), edificios públicos (un macellum del que se conserva un epígrafe, e indirectamente un foro -en el que se debía encontrar, probablemente, el pedestal de Q. Manlio Celsino- y un templo dedicado al culto imperial -por la mención del flamen-), construcciones monumentales (un gran depósito hidráulico de dos millones de litros en la partida de Torres -Fig. 6-, la torre funeraria de Sant Josep, el recientemente descubierto monumento de sillería de l'Almiserà o las termas monumentales de sillería -Fig. 8- que están saliendo a la luz en la calle Canalejas - sin duda ubicadas en un contexto urbano-), un denso poblamiento altoimpe- rial con numerosas villae suburbanas y rústicas, un destacado puerto marítimo con una gran área de almacenes costeros en la plaça de Sant Pere (Fig. 6) y otras características de las ciudades con estatuto jurídico. Lo realmente importante es la posesión de una categoría urbana, con todas sus implicaciones ${ }^{16}$, que en el caso del enclave romano de Villajoyosa nadie duda.

El propio tipo de pedestal, pesado, honorífico, suele ser indicativo -como decimos- de la existencia de una ciudad con categoría jurídica, puesto que solían colocarse en lugares públicos urbanos, mientras que las placas funerarias, a veces con texto muy similar, pueden aparecer también en villae rusticae o incluso en el territorium de una ciudad distinta a la del homenajeado (vid. Puerta y Stylow, 1985, 229 ss.).

Sobre este pedestal se ha discutido la cuestión de una línea actualmente perdida, la cuarta, en la que el CIL (II 3571, 958) recoge la información del llamado Anonymus Montfauconii ${ }^{17}$, desarrollándola [IIvir(o) III, fla], lo que nos daría un triple duumvirato para este personaje. La lectura de la siguiente línea [mini III] no deja dudas sobre el triple desempeño de un flaminado. Corell (1999, 183-184) opina que la lectura del Anónimo de Montfaucon no es más que un desarrollo supuesto por su autor, y que la línea 4 falta desde que el epígrafe es conocido. Este autor afirma que la lectura II VIR III FLA (aceptada por Rabanal y Abascal, 1985, 218 s., n 54 y por Abad y Abascal, 1991, 117-118, n 63) es imposible por falta de espacio, pero una restitución hipotética realizada por nosotros utilizando las mismas letras de la inscripción deja bien claro que, por el contrario, este texto cabe perfectamente en la línea 4 (Fig. 7) -incluso diríamos que da un mayor equilibrio a la inscripción en el campo epigráfico-, con lo que no vemos motivo para restituir una mención a un único duumvirato [II v(iro), fla $]^{18}$, como propone Corell, y dudar de la lectura del Anonymus. En cualquier caso, para la cuestión que aquí nos ocupa, lo de menos es la cantidad de veces que Quinto Manlio Celsino desempeñó el duumvirato: lo realmente significativo es el consenso existente en que la línea

16. Sobre las distintas categorías de las ciudades romanas vid. Richmond, 1957, 5-8.

17. Un manuscrito consultado por E. Hübner en París, en el que se recogían inscripciones hispanas descritas por informadores anónimos (vid. Abad y Abascal, 1991, 117118 y 219).

18. Alföldy (2003, 49, nota 90) corrige IIvir(o) fla], lo que nos parece, en cualquier caso, más conforme a la abreviatura habitual de este cargo. 
perdida menciona este cargo político. En efecto, el flaminado era el culmen del cursus honorum municipal, por lo que es de suponer que, con anterioridad a este sacerdocio, Celsino debió haber alcanzado la responsabilidad de duumvir.

La repetición de cargos, de hecho, responde a lo reducido de las élites locales en ciudades de pequeña entidad como la de Villajoyosa. Es bien sabido que la promoción de homines noui era poco frecuente -aunque más habitual en las provincias que en la propia Roma- (Abascal y Espinosa, 1989, 44) ${ }^{19}$.

También la mensa de un macellum local, a la que hemos aludido más arriba, confirma la existencia de una ciudad en el término municipal de Villajoyosa: de hecho, este tipo de construc-

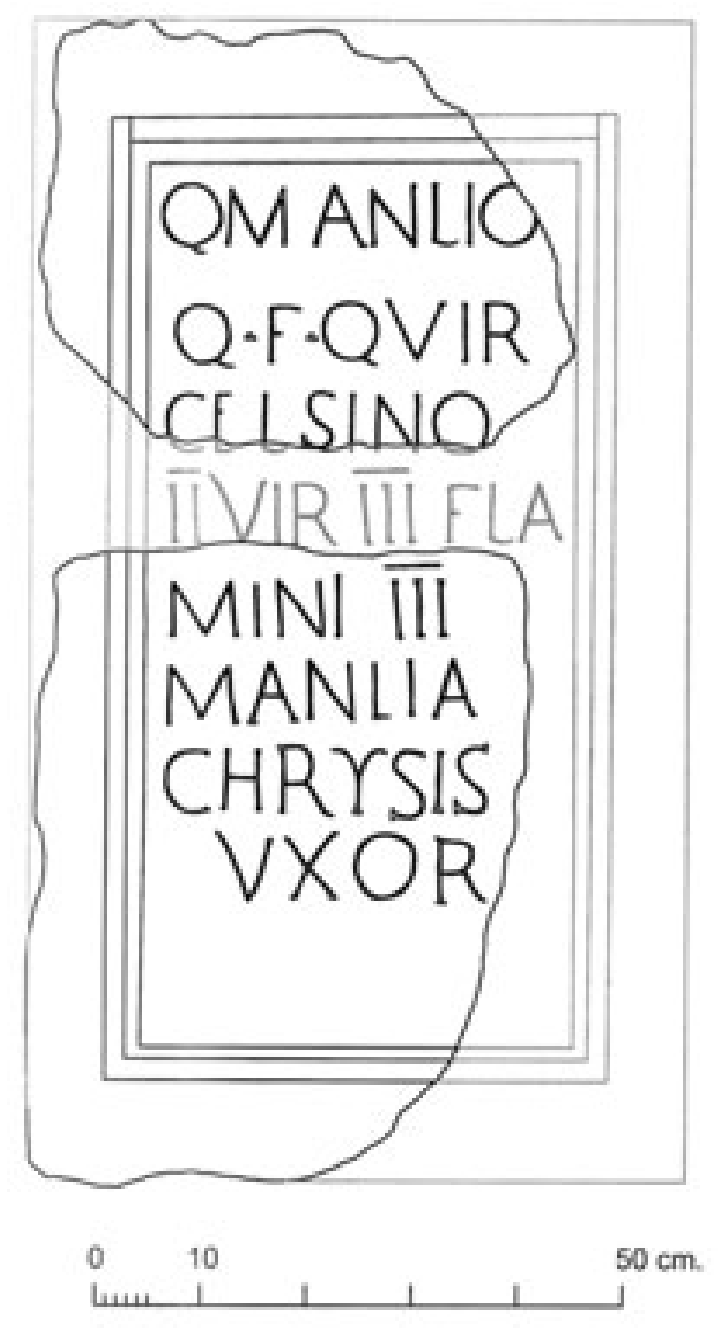

Figura 7: pedestal honorífico dedicado a Q. Manlio Celsino, con la posible restitución de la $4^{\mathrm{a}}$ línea (perdida).

19. La existencia de Ilviri y no de IIIlviri no es de extrañar, pues suele responder a particularismos locales de difícil explicación (ibíd., 42). ciones es propio de espacios de carácter público en un entorno urbano.

Distintas razones nos hicieron proponer en nuestra Tesis doctoral (Espinosa 1996a, 735736) que esta ciudad se ubicaba en la partida de Torres de Villajoyosa, en el yacimiento que denominamos Torres I, junto al último tramo del río, y a escasa distancia del monumento funerario conocido como Torre de Sant Josep, que pertenecería, según aquella hipótesis, a una necrópolis urbana. El dato sobre el lugar de hallazgo de la mensa del macellum aportado por Escolano, si fuera correcto, dejaría pocas dudas al respecto, pero se trata de una indicación vaga, que no nos parece, por sí sola, lo bastante sólida ${ }^{20}$.

Otros núcleos destacarían dentro de la propia Ilanura litoral de Villajoyosa: en especial lo que interpretábamos (Espinosa, 1996, passim) como un probable vicus portuario bajo la actual ciudad y otro agrícola unos kilómetros al interior, cerca del propio río de Torres ${ }^{21}$. Sin em-

20. En nuestra Tesis doctoral (1996) y en otros lugares hemos interpretado el texto de Valcárcel sobre la inscripción de Q. Manlio Celsino (supra) erróneamente: en efecto, ya hemos explicado cómo la referencia que da este autor al lugar del hallazgo del pedestal, que induciría a situarlo en la partida de Torres, cerca de la Torre de Sant Josep, no parece correcta, y no puede venir en apoyo del dato que ofrece Escolano, como creíamos.

21. Este último núcleo cuenta con, al menos, dos epígrafes conocidos - uno de ellos honorífico (CIL II 3576; Rabanal y Abascal, 1985, 55 -como igualmente opinamos-); o bien funerario según J. Corell, 1999, 189) y otro funerario (Abad y Abascal, 1991, 123-124, n 72; Corell, 1999, 197, $\left.n^{\circ} 115\right)-$, así como una cierta entidad arqueológica desde la época ibérica. En esta zona propusimos en nuestra tesis doctoral la ubicación del probable vicus, en cuyas inmediaciones se erigió el posterior grupo de asentamientos islámicos que podemos identificar con el Torres de las fuentes cristianas de la Reconquista, excavado hace unos años por J. Ramón García (2005) -tres alquerías de los s. XI-XIII, entre las cuales destaca la del Tossal de l'Almiserà, con una mezquita asociada a un cementerio-, y que de alguna manera parece perdurar desde la Antigüedad hasta el s. XIII. Podemos pensar que el nombre del núcleo romano de esta zona (quizá asociado al yacimiento denominado Camí la Vila II, donde hay restos de una villa con balnea), que probablemente constituyó un vicus agropecuario muy próximo a la ciudad durante el Imperio, fuese Turris o algún compuesto de esta palabra, lo que explicaría que una población islámica conservara un nombre de origen latino. No obstante, el topónimo pudo trasladarse también, como veremos, desde un asentamiento costero romano (Torres I) hasta el núcleo islámico, al interior, ambos junto al cauce del río. J. Corell (1999, 181-182) cita un ara, que atribuye a Villajoyosa, con la inscripción Turri(s) Genio, que podría estar dedicada a una divinidad protectora de un lugar llamado Turris. Sobre los vici en la Marina Baixa, vid. Espinosa, 1996 y un breve resumen de la cuestión en Espinosa, Sáez y Castillo, 2006, 58. 
bargo, como veremos a continuación, recientes hallazgos apuntan a que el núcleo urbano romano corresponde en realidad con el yacimiento sobre el que se alza la actual ciudad de Villajoyosa, y no con el asentamiento de la partida de Torres.

\section{LAS RECIENTES EVIDENCIAS ARQUEOLÓGICAS}

En 2005 se excavaron unos baños altoimperiales de cierto porte en el yacimiento Jovada I -bajo la dirección de D. Ruiz, y Amanda Marcos, así como uno de los hipocaustos bajo la dirección de Eduardo López-, quizá asociados a la cercana villa de Jovada II o quizá de carácter público, inmediatos al asentamiento que subyace a la ciudad actual de Villajoyosa (la excavación futura de la mitad septrentrional de este edificio podría aportar más luz a su titularidad pública o privada).

Las termas monumentales que hemos mencionado más arriba, en curso de excavación en la calle Canalejas, son propias de un entorno urbano, de modo que -en el momento actualparece seguro que el municipium se encuentra en este lugar, bajo el casco urbano de Villajoyosa, junto a la vieja ciudad ibérica que subyace al casco antiguo. Los sondeos que próximamente se realizarán en el yacimiento de Torres I permitirán comprender el porqué de la ubicación de la necrópolis monumental a la que -si son ciertos los datos aportados por Valcárcel, que realizó excavaciones en la zona- pertenece la Torre de Sant Josep, situada a $3 \mathrm{Km}$ al E del casco urbano de Villajoyosa, y comprender su relación con la ciudad romana.

La población ibérica, precursora de aqueIla, es igualmente relevante, como dejan ver claramente sus necrópolis de Poble Nou y de Casetes, parcialmente excavadas. En la necrópolis del Poble Nou (Espinosa, Ruiz y Marcos, 2005; Ruiz Alcalde y otros, en prensa) se han excavado dos sectores en los que encontramos tumbas del s. V (principalmente de su primera mitad), algunas del s. IV y sobre todo un elevado número del s. II y I a.C. Las tumbas más antiguas, en fosa rectangular revestida interiormente de adobes 0 de arcilla, han proporcionado numerosos objetos suntuarios, como collares de oro orientalizantes de la segunda mitad del s. VI, collares de esteatita con representación de divinidades egipcias, un colador etrusco de bronce del s. VI e incluso tres copas de figuras negras tardías (del «pintor de Haimón»), de comienzos del s. V. Algunas tumbas de Poble Nou alcanzan el s. III d.C., pero la fase imperial de la necrópolis es todavía poco conocida.

De uno de los sectores excavados de la necrópolis de les Casetes, el más septentrional, se ha publicado ya un primer avance (García Gandía, 2005), y se encuentra en preparación la publicación de la memoria del tramo meridional, excavado recientemente bajo nuestra dirección, en la Plaza de la Creueta. En conjunto, esta necrópolis muestra una longitud de más de $500 \mathrm{~m}$ y se dispone a los lados del camino de entrada a la ciudad ibérica, que después continuó habitada durante el Imperio. Esta necrópolis arranca del s. VII a.C. y se desarrolla hasta al menos el s. IV d.C. y probablemente más tarde. En diferentes sectores se agrupan tumbas antiguas, hasta el s. V a.C., y otras del Ibérico Final (s. II-I a.C.), y sobre estas últimas otras altoimperiales entre las cuales se detectan algunas tardías, de los s. III-IV.

El núcleo urbano ibérico al que pertenecen estas necrópolis se encuentra sin duda bajo el casco antiguo de Villajoyosa, un cerro costero situado junto a la desembocadura de uno de los dos ríos de la comarca y frente a una extensa playa con un pequeño refugio proporcionado por la punta d'Alcocó y sobre todo con buenas condiciones para el fondeo y el comercio marítimo (Espinosa, Sáez y Castillo, 2006, 42-44). A pesar de que algunas excavaciones de salvamento no han permitido localizar restos, como consecuencia de la transformación provocada por la erección del núcleo medieval, sí hemos podido localizar en otros solares estratos con materiales y estructuras ibéricos que demuestran la existencia de un gran yacimiento de esta época (vid. Espinosa, Ruiz y Marcos, 2005).

Durante la época romana el cerro y su entorno continuaron poblados, al menos hasta el s. VI d.C., como atestiguan la cercana Villa de Plans, algunos materiales sin contexto de la excavación de la plaza de la Creueta (Fig. 8) y la última fase del yacimiento de Jovada ${ }^{22}$. Hemos podido documentar la existencia de estructuras domésticas del Ibérico Final y de otros restos de un poblamiento disperso, en torno a este cerro, ya desde el Ibérico Pleno.

Durante el Imperio, junto a la vieja ciudad ibérica se desarrolla un destacado núcleo romano urbano, de marcado carácter industrial y co-

22. Información inédita de D. Ruiz y Amanda Marcos, a quienes de nuevo agradecemos el dato. 


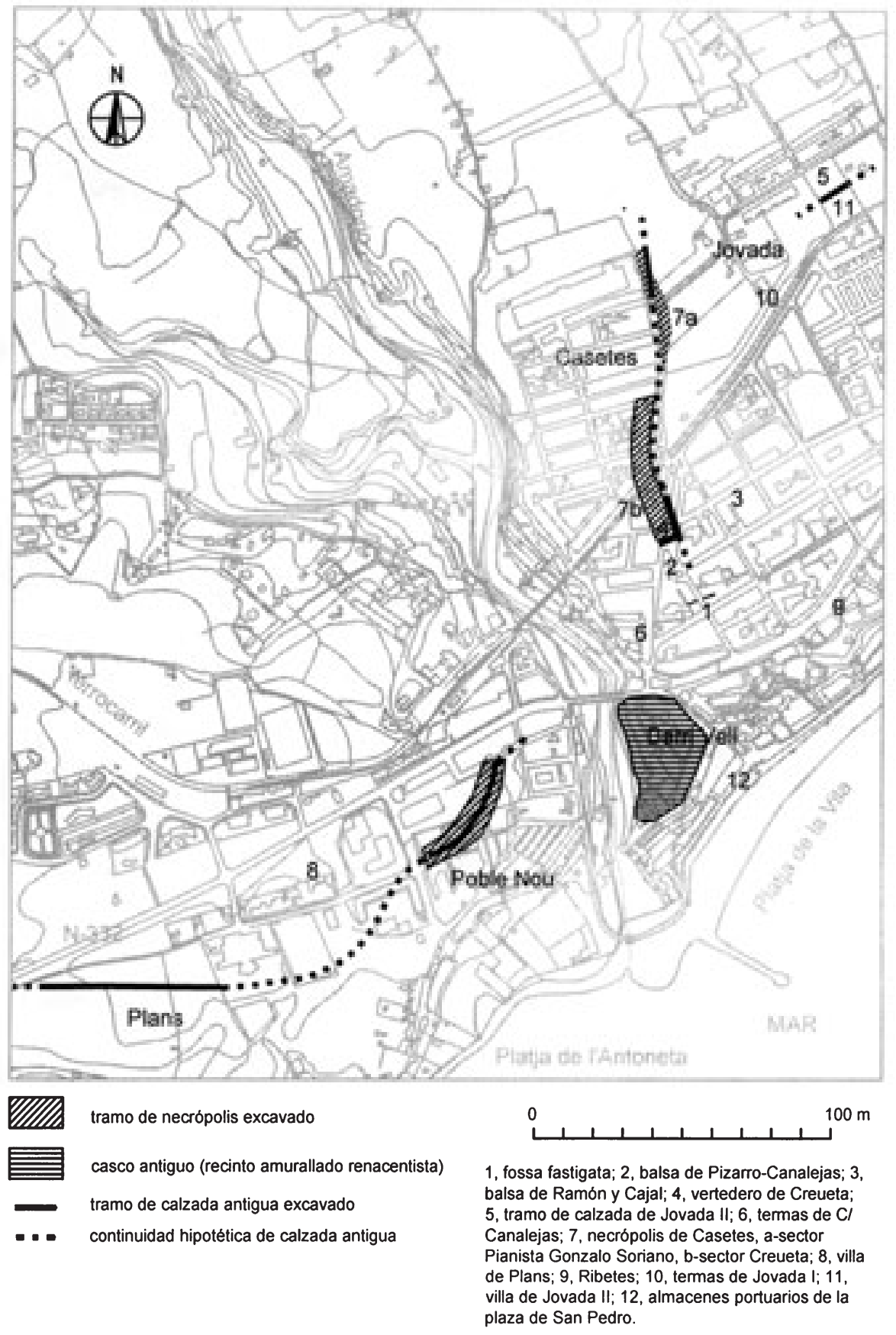

Figura 8: yacimientos ibéricos y romanos del casco urbano de Villajoyosa.

mercial. En su entorno se concentran un buen número de villae (Barberes Sur, Plans, Ribetes, Jovada II, etc.) (Fig. 6) en las que hay indicios de una orientación económica en relación con la fabricación de salazones de pescado, y otras más al interior (como la villa monumental de Xauxelles, vid. Espinosa, 1991 y 1996) de carácter más marcadamente agrícola.

\section{LOS TOPÓNIMOS ALONÍS, ALONAI Y ALLON Y SU EQUIVALENCIA}

No disponemos ni tan siquiera de la más mínima pista material respecto al nombre de la ciudad ibérica y de su heredera romana, a pesar de la relativamente abundante epigrafía latina, derivada de la categoría jurídica de este enclave. Sin 
embargo, el contraste de la realidad arqueológica de Villajoyosa con el análisis de las fuentes permite, en nuestra opinión, considerar la identificación de este núcleo con la Alonís/Alonai/Allon de las fuentes como la más probable (Espinosa, 1996a, 19 ss.; 1998b y 2006, 42-44 y 51-52).

Llobregat (1983, 229; idem 1984, 233) propuso la identificación de estos topónimos antiguos con Santa Pola, después ampliamente aceptada (cf., por ejemplo, Rouillard, 1991, 303-306 o Morote, 2002, 188-189). A. Rodríguez Colmenero (1985, 411), por su parte, planteó si Portus Ilicitanus no sería un término oficial que acabaría imponiéndose al original, Alonai -nos parece, en cualquier caso, una interpretación algo forzada-. P. Moret (2000, 239 y 241), en fin, ha desarrollado, recientemente, una argumentación muy elaborada a favor de que Alonís y el vicus portuario del Portus Ilicitanus son el mismo enclave -como ya se deducía de la hipótesis de Llobregat-.

En el libro IV del Ravennate (Rav. IV.42 -304,16-) Allon se sitúa a continuación de la serie Dionio (=Dianium) - Lucentes (=Lucentum) - Leones, e inmediatamente antes de Hilice (=Ilici) (Fig. 9). Como el propio E. Llobregat reco- nocía, la identificación con Santa Pola depende de la validez del emplazamiento de la ciudad en esta guía de caminos (cf. Roldán, 1973, 111-142; Llobregat, 1983, 229; ídem 1984, 133; Abad y Abascal, 1991, 20-21), de la que no es difícil dudar, dadas las imprecisiones del libro IV -aunque P. Moret $(2000,241)$ considera el Ravennate la fuente más fiable en lo que toca al orden de los lugares-. De hecho, el libro V (Rav. V 3 -343,6-), -más exacto desde los puntos de vista de la grafía y de la exactitud geográfica, según $\mathrm{E}$. Llobregat (1983, 229)- no menciona Allon (aunque sí Ad Leones, como el libro IV) (Fig. 9).

En la Guidonis Geographica $(82,515,12)$, otra guía de caminos del s. IX d.C., sucede algo parecido al libro $\mathrm{V}$ del Ravennate. E. Llobregat (1983) interpretó Ad Leones / Leones / Ad Lennes, mencionada en los tres textos, como una población litoral entre Lucentum e Ilici.

Por su parte, Lorenzo Abad (1984, 133) se planteó si Leones (Rav. IV 42 -304,15-) -con sus variantes Ad Leones (Rav. V $3-343,6-$ ) y Ad Lennes (Guidonis Geographica 82, 515, 12)- y Allon no eran la misma población, con el nombre contraído en el segundo caso. Anteriormente,

\begin{tabular}{|c|c|c|c|c|c|}
\hline \multicolumn{2}{|c|}{$\begin{array}{l}\text { RAVENNATE IV, } 42 \text {, } \\
\text { PP. 342-343 }\end{array}$} & \multicolumn{2}{|c|}{$\begin{array}{l}\text { RAVENNATE V, 3-4, } \\
\text { PP. 303-305 }\end{array}$} & \multicolumn{2}{|c|}{$\begin{array}{c}\text { GUIDONIS GEOGRAPHICA } \\
\text { PP. } 514.81 \text { Y } 515.82\end{array}$} \\
\hline \multirow[t]{13}{*}{342} & 5 Tarraconem & \multirow[t]{3}{*}{303} & 13 Tarsagona & \multirow[t]{6}{*}{514.81} & 20 Terragona \\
\hline & 6 Saltum & & 14 Saguntum & & 21 Saltum \\
\hline & 7 Pinon & & 15 Pinos & & 22 Pinum \\
\hline & 8 Trea Capita & \multirow[t]{17}{*}{304} & 1 Orea Capita & & 23 Tria Capita \\
\hline & 9 Dertosa & & 2 Dertusa & & 24 Dertosa \\
\hline & 10 Lubricatum & & 3 Rubricatum & & 25 Laubricatum \\
\hline & 11 Hildum & & 4 Hildum & 515.82 & 1 Idum \\
\hline & 12 Intibili & & 5 Saguntum & & 2 Intibili \\
\hline & 13 Saguntum & & 6 Valentia & & 3 Saguntum \\
\hline & 14 Valentia & & 7 Portum. Sucrone & & 4 Valentia \\
\hline & 15 Sucrone & & 8 Asterum & & 5 Sucrone \\
\hline & 16 Dio & & 9 Setavum & & 6 Dinium \\
\hline & 17 Alternum & & 10 Turres & & 7 Alterum \\
\hline \multirow[t]{8}{*}{343} & 1 Setabi & & 11 Eloe & & 8 Setabi \\
\hline & 2 Turres & & 12 Celeret & & 9 Turres \\
\hline & 3 Edelle & & 13 Dionio & & 10 Edelle \\
\hline & 4 Celeri & & 14 Lucentes & & 11 Celeris \\
\hline & 5 Lucentes & & 15 Leones & & 12 Ad Lennes \\
\hline & 6 Ad Leones & & 16 Allon & & 13 llice \\
\hline & 7 llice & & 17 Hilice & & 14 Cartago Partaria \\
\hline & 8 Carthago Spartaria & 305 & 1 Cartago Partaria & & \\
\hline
\end{tabular}

* Var. Portum Sucrone.

Según J. M. Roldán (1973), recogido por E. A. Llobregat (1983).

Figura 9: las vías romanas del sur del País Valenciano según el Ravennate y la Guidonis Geographica. 
Holder (1894-1916, III, 574), y posteriormente Rabanal (1985a, 364), Tovar (1989, t. 3, 201) y Corell $(1999,176)$, entre otros, han aceptado esta igualdad. La contradicción aquí estriba en la mención de Leones y Allon en el libro IV del Ravennate. P. Moret (2000, 241 y nota 18) opina que $\mathrm{Ad}$ Leones es «sans doute un simple relais, non localisé».

M. A. Rabanal (1985a, 364) propuso abiertamente la equivalencia Alonae = ciudad situada en término de Villajoyosa, para, unas páginas más adelante, en la misma publicación, mostrarse dubitativo entre las áreas Benidorm-Villajoyosa y Alicante-Santa Pola (ibid., 366). También Reynolds (1993, 89, $\left.n^{\circ} 218\right)$ sugiere que «this municipium is so far unnamed, perhaps it is to be identified as Alonis».

La primera mención a Alonís la encontramos en Artemidoro de Éfeso, un geógrafo griego que viajó a España hacia 100 a.C. y que, según el resumen de su obra redactado por Esteban de Bizancio hacia 520, habla de aquélla como «isla y ciudad de Massalia», afirmando que el gentilicio es «alonitas». La misma Alonís puede ser, como apuntábamos al principio, una de las «tres fundaciones de massaliotas» de las que «la más conocida es Hemeroskopeion», a las cuales alude Estrabón (III, 4, 6) en el siglo I a.C. -P. Moret (2000, 254) opina, sin embargo, que la Alonís de Artemidoro «n'a probablement rien à voir avec le pasaje de Strabon concernant les «trois petites villes massaliotes»».

Sobre estas supuestas colonias existen serias dudas por la mayor parte de los investigadores (Tarradell, 1965; ídem, 1988, 75-81; Morel, 1966; Martín, 1968; Llobregat, 1969; Uroz, 1981, 254-256; Pena, 1989), aunque algunos autores aceptan su existencia (vid. Rouillard, 1991). En general, como hemos visto más arriba, se tiende a admitir la posibilidad de pequeños establecimientos o barrios helénicos de carácter comercial inmersos en poblaciones ibéricas costeras.

E. A. Llobregat (1983b, 238-239) interpretó Alternum como "otro camino, desvío», una alusión a esta vía secundaria costera, que según él volvería a su origen desde su hipotético final en Dianium, pero que, según otros investigadores, supondría la ruta alternativa para descender hacia los territorios del sur, conectando las ciudades costeras de Dianium y Lucentum (Arasa y Rosselló, 1995; Brotons, 1996) -nosotros mismos apoyamos esta hipótesis en anteriores ocasiones (vid. Espinosa 1996)-.

Brotons $(1996,71)$ interpreta la Allon del Ravennate como una transliteración al latín del pronombre griego "'A $\lambda \lambda$ ov (neutro de ' $\mathrm{A} \lambda \lambda \mathrm{\alpha}$, 'otro, diferente'), y por tanto como una anotación del compilador para indicar un camino distinto a la Vía Augusta.

Corell $(1999,176)$ aprovecha esta lectura para ir más allá, y proponer que Alterum/Alternum/Asterum son una traducción al latín de lo que en realidad no era un pronombre traducible, sino el nombre de una ciudad, Allon. El principal problema que plantea esta interpretación es que, en este caso, Allon aparecería citada por tres veces en el libro IV del Ravennate, bajo distintas formas (Asterum, Leones y Allon), y por dos veces en el libro V y en la Guidonis Geographica. J. Corell desarrolla una interpretación pormenorizada de esta hipótesis (1999, 178-179), que ofrece una posible explicación al problema, aprovechando la interpretación de Celeret/Celeris/Celeri del Ravennate y de Guidonis Geographica planteada por Antonio Poveda $(1991,69)$ como «camino más rápido», es decir, como un atajo. Éste, según la interpretación de Corell, se dirigiría a Lucentum desde un punto indeterminado de la calzada principal, entre Ad Ello y Aspis, y desde allí hacia Allon; mientras Poveda interpretaba el tramo más rápido (celeris) como el que cruzaría la sierra de Crevillente por el antiguo camino de Castilla -propuesto como trazado de la vía por V. Gonzálvez (1974).

Otra opción, que planteamos aquí, es que Celeris indique un punto (en el entorno de Aspis, que ya no mencionan el Ravennate ni la Guidonis Geographica) en el que hubiese un atajo a través de la sierra del Tabaià hacia Ilici, mientras el otro ramal (quizá el principal, más cómodo pero considerablemente más largo y, por tanto, más lento) rodeaba la sierra por el este y permitía alcanzar Lucentum y desde allí Villajoyosa (Allon) o bien bajar igualmente hasta Ilici.

Lorenzo Abad $(1984,198)$ detectó también una contradicción en la reducción de Allon a Santa Pola: la mención simultánea de Illikitanos Limen $^{23}$-con seguridad Santa Pola- y de Alonai en un texto de Claudio Ptolomeo (II, 6, 14). Si aceptamos que son diferentes -lo que nos parece la opción más sencilla y lógica-, la segunda se queda de nuevo sin ubicación concreta. El orden en que Ptolomeo coloca las ciudades de nuestras costas parece abogar por una ubicación de Alonai inmediatamente al norte de la desembocadura del río Taber (=Tader, Segura), y entre ésta y la del río Saitabis. El desorden, sin embargo, es evidente, porque Saetabis aparece al sur del Illikitanos Limen y Lucentum aparece

23. En latín, Portus Illicitanus. 
al sur de Carthago Noua, todos ellos enclaves de ubicación conocida y contraria a la que indica este autor. El orden en el que figura Alonai no nos parece aquí, por tanto, un argumento sólido en el debate sobre su ubicación.

Tengamos ahora en cuenta dos hechos: por una parte, Pomponio Mela, autor hispano del s. I d.C., al describir la costa de norte a sur, se refiere a Allon, Lucentia -es decir, Lucentum-e Ilici, en un orden que, si es correcto, coloca a la primera al norte de la segunda, dentro del Sinus Illicitanus (Schulten, 1922, 231-232; ídem, 1955; Espinosa, 1996). P. Moret $(2000,240)$ advierte, sin embargo, que Mela «ne respecte pas toujours une progresión géographique stricte du nord vers le sud», aunque nos parece algo exagerado afirmar que «l'ordre des noms des villes ne signifique rien chez cet auteur».

En segundo lugar, tanto Lucentum como Ilici son ciudades con estatuto jurídico -municipio de derecho latino pre-flavio y colonia inmune, respectivamente-. Queremos resaltar el hecho de que la única ciudad romana que alcanzó una categoría urbana privilegiada -municipio de derecho latino con Vespasiano, hacia 73/74- que conocemos en el Golfo Ilicitano, además de aquellas dos es, precisamente, la existente en término municipal de Villajoyosa ${ }^{24}$.

La mención reiterada de Allon en las fuentes nos está indicando una mayor importancia de esta ciudad, en el contexto regional, que la de otras poblaciones, como bien apuntó M. Olcina (1990a, 184-185). De igual forma descuella el núcleo romano que nos ocupa, en el ámbito de lo que actualmente es le provincia de Alicante, tanto por el número de epígrafes -tan sólo superada por Ilici, Dianium y Lucentum, por este orden (cf. Abad y Abascal, 1991; Corell, 1999)- como por la categoría jurídica. Nos parece, por tanto, plausible identificar el topónimo sin ubicar y el enclave sin nombre, ambos privilegiados, porque además el análisis de las fuentes aporta sólidos argumentos a favor.

En cuanto a la isla mencionada por Artemidoro de Éfeso, quizá se trate de la de Benidorm, visible desde Villajoyosa, aunque no nos consta

24. Estos argumentos fueron apuntados por L. Abad (1984, 197-198) para plantear la posibilidad de la identificación de Alona con el Tossal de Manises, cuando todavía parecía seguro que Lucentum no se encontraba allí, sino en el barrio alicantino de Benalúa. Actualmente la evidencia arqueológica permite rechazar esta hipótesis, y al mismo tiempo asegurar la equivalencia Lucentum=Tossal de Manises (Abad Casal, 1990, 141 ss.; Olcina, 1990a; Abad y Abascal, 1991, 48-49). que estuviera ocupada en época ibérica ${ }^{25}$. P. Moret rechaza esta posibilidad, argumentando precisamente que el análisis de las fuentes griegas indica que Alonís debía ser una isla habitada, con una cierta entidad poblacional, relacionada con las rutas marítimas, lo que choca -como él mismo apunta- con las condiciones naturales de las islas de Benidorm y de Tabarca: en efecto, ambas carecen de leña y de agua, la primera tiene fuerte pendiente y mal atracadero y fondeadero, la otra es peligrosa para la navegación y con mal tenedero (vid. Pérez Burgos, 1996, 179; Gutiérrez Lloret, 1999a, 91; y Espinosa, Sáez y Castillo, 2006, 52, con bibliografía anterior).

El origen del nombre Allon/Alonís/Allonaí no es claro. Recientemente esta cuestión ha sido minuciosamente analizada por P. Moret (2000, 250 ss.), a cuyo trabajo remitimos para más detalles. Tradicionalmente se ha propuesto un origen griego (Tovar, 1989, t. 3, 205), bien en relación con el vocablo griego alonía (era) (Hübner, en RE I, 1595) bien con “' $\lambda \varsigma$ ('sal') (Schulten, 1922, 232) o con “ $\alpha \lambda \omega \nu$ (huerto) (vid. Corell, 1999, nota 188). Precisamente " $\alpha \lambda \varsigma$ sirvió para defender la ubicación de Allon en Santa Pola y en Guardamar, por la existencia de salinas en sus inmediaciones, pero la derivación de esta palabra, con espíritu áspero, a Alonís (con espíritu suave) es forzada, como opinan Corell (1999) y Moret (2000). E. Llobregat (1990, 68, 97) propuso un origen ibérico de la palabra, que a Moret le parece, igualmente, el más probable.

La antigüedad del enclave ibérico aboga, efectivamente, por un nombre original indígena, no griego, aunque no sabemos cuál de las variantes conocidas se aproximaría más a aquél. La forma correcta del topónimo romano ha sido analizada por Corell $(1999,176)$, quien propone que el nominativo es Allon (tal como aparece en el Ravennate, 304, 16), y que la forma Allonem (utilizada por Mela) es el acusativo, lo cual parece indiscutible.

Moret (Ibíd., 252) propone Alon, con una 'l', puesto que esta grafía y sonido geminados no son característicos de la lengua ibérica. Como bien apunta Piere Moret $(2000,241)$, la repetición de esta letra puede ser obra de Mela, que igualmente habla de Bello (II, 96) refiriéndose a Baelo o Belo Claudia. De esta forma, el nombre, tanto ibérico como romano, pudo ser Álon, y el resto (Alonís, Alonai...) adaptaciones al griego

25. Según Gabriel Segura, que ha dirigido recientemente unos sondeos arqueológicos en la isla, se documentan en ella dos fases de ocupación: una entre finales del s. I y comienzos del s. II d.C. y otra posterior de los s. IV y V. 
(la feminización en Alonai es un fenómeno muy corriente, como sucede con Lucentum en el texto de Mela, donde leemos Lucentia). Leones, Ad Leones, etc. -si aceptamos su interpretación como variantes del mismo nombre- pueden ser pluralizaciones del original (deformaciones, por tanto, de Alones o Allones), algo que también encontramos, como hemos visto anteriormente, en muchos casos en las fuentes clásicas (Lucentes, sin ir más lejos, en el Ravennate).

A juzgar por los ajuares del sector junto a la calle Pianista Gonzalo Soriano de la necrópolis de Casetes, excavado por J. R. García Gandía (2005), el origen de la ciudad protohistórica podría alcanzar, al menos, finales del s. VII a.C., mientras que el s. VI a.C. está documentado tanto en esta necrópolis como en la de Poble Nou. No obstante la presencia abundante de elementos orientalizantes, e incluso de cerámica ática de figuras negras en Poble Nou, parece claro que las tumbas son en general indígenas -salvo quizá algún caso, como la tumba 17 del sector que hemos mencionado (García Gandía, 2003 y 2005)-. Algunos elementos más, ciertamente extraordinarios en el contexto arqueológico del levante español -de por sí la presencia de vasos de figuras negras ya resulta elocuente-, como un colador etrusco de bronce del s. VI a.C. (Marcos y Ruiz, 1995, fig. 3; Espinosa, Ruiz y Marcos, en prensa), nos remiten, probablemente, a una cierta intensidad del comercio griego, e inciden en la posibilidad de que existiese alguna presencia permanente de comerciantes helenos, en el contexto colonial de finales del s. VI y el s. V a.C., en la ciudad ibérica, como sugiere el texto de Artemidoro.

Con un poblamiento ibérico muy importante, y cada vez mejor conocido ${ }^{26}$, podemos concebir la continuidad durante el Imperio, al menos nominal, con respecto a una Alonís o Alon (según Moret) de época ibérica. A pesar de la abundante epigrafía conservada, todavía no hemos tenido la suerte de encontrar una mención explícita, como sí ha ocurrido en los casos de las vecinas Lucentum y Dianium. Aunque los recientes hallazgos han desatado una gran expectación y sin duda permiten afirmar que Villajoyosa tiene mucho

26. El desarrollo de las investigaciones vino de la mano de un hito fundamental en la protección del patrimonio de Villajoyosa: la aprobación en 1992 de la Normativa Municipal sobre Remoción de Terrenos en Zonas Arqueológicas publicada en el Boletín Oficial de la Provincia $n^{\circ} 245$, del 26 de octubre de 1992, p. 9-11 y revisada en 1994. Este documento constituyó la base del catálogo de bienes y espacios protegidos (con tres revisiones desde 1998, la última de ellas en curso) que decir a la arqueología protohistórica y clásica de la Península Ibérica, y promete albergar importantes claves para nuestro conocimiento de algunos fenómenos culturales como los influjos orientalizantes en las poblaciones preibéricas e ibéricas; a pesar de ello, como decimos, y de que los argumentos a favor de la hipótesis que defendemos nos parecen bastante sólidos y los más coherentes con la realidad arqueológica actualmente conocida al sur del País Valenciano, quizá convenga mantener una cierta cautela científica, por mínima que ésta sea, evitando convertir la hipótesis Alonís = Allon = Villajoyosa en una aserción, mientras una prueba directa no lo autorice.

En cuanto al texto de Pomponio Mela (II, $6,93)$, creemos que lo que este autor está haciendo es una relación de ciudades destacadas de la costa. Probablemente, en las fechas en las que él escribe la de Villajoyosa no poseía todavía un estatuto municipal (no lo tendrá, a lo que parece, hasta Vespasiano, un cuarto de siglo después), pero la pujanza poblacional y económica de la ciudad ibérica en los dos últimos siglos de la República resulta evidente, a juzgar por el gran número de tumbas de las necrópolis y por la riqueza de sus ajuares, así como por las importantes obras públicas que se ejecutan hacia comienzos del s. I a.C., y que ya hemos mencionado (pavimentación y delimitación de las tres calzadas principales hacia las tres comarcas vecinas, reedificación del santuario del Tossal de la Malladeta, etc.), y a las que siguen otras en época augustea -como la construcción del depósito de opus caementicium de la partida de Torres, de dos millones de litros (Olcina, 1990b)- y el establecimiento de numerosas villae (como Barberes Sud, Xauxelles, Jovada II, Camí la Vila $y$, probablemente, Plans) en la primera mitad del siglo. También el puerto da señales de una importante actividad en época republicana y con la llegada del Imperio (Castillo, Espinosa y Sáez, 1998, 124-125 y más recientemente, Espinosa, Castillo y Sáez, 2006, 42, con toda la bibliografía anterior).

Precisamente, la concesión del estatuto municipal a la ciudad romana de Villajoyosa en época Flavia se deriva necesariamente de ciertos méritos o requisitos básicos, como debieron ser: la existencia de una población importante y destacada de su entorno; un territorio claramente delimitado vinculado a ella; una élite local lo suficientemente numerosa, rica y poderosa como para tomar las riendas de una administración municipal romana; y una realidad urbana y urbanística ya existente, que seguramente se monumentalizó especialmente a partir de la 
municipalización. De cualquier modo, es claro que el oppidum de Villajoyosa ya ejerció un papel de lugar central en la comarca de la Marina Baixa durante la época ibérica, y que las élites indígenas debieron mantener una fuerte pujanza hasta el Imperio (Espinosa, 1996; Martínez García, 2005, 42). Este importante oppidum de origen ibérico pudo depender de Dianium -como hemos propuesto en alguna ocasión (Espinosa, 1996 y 1999)-, o mantener, con anterioridad al Decreto de Vespasiano, una independencia de las ciudades de alrededor (Lucentum y Dianium, con estatuto jurídico romano más antiguo), lo que en realidad se ajustaría mejor a su vitalidad en época republicana, a su probable mención en el texto de Mela, y a la posterior promoción en época flavia (vid. Le Roux, 1990, 40-43).

La ciudad de Villajoyosa ya era tal, sin duda, antes de la concesión del estatuto municipal. Era un núcleo destacado en la costa alicantina, como lo eran las otras ciudades (Dianium, Lucentum e Ilici), y esa entidad le hizo merecedora del privilegio concedido por Vespasiano. Por tanto, no estamos hablando de un simple vicus, sino de un enclave que ejerce de lugar central de una comarca, del mismo modo que el territorium de Lucentum debió coincidir aproximadamente con l'Alacantí y el de Dianium con la Marina Alta y La Safor, o el de Ilici con la Vega Baja y el Vinalopó. Esta distribución de un lugar central por cada una o varias comarcas lo apreciamos ya en época ibérica (cf. por ejemplo Grau, 2002 para el caso de La Serreta y l'Alcoià-El Comtat), y se percibe claramente en la romana, en general en el territorio valenciano (vid. Olcina, 1990a, 182; Corell, 1999, 35).

Resultaría extraño que Mela hubiese citado el vicus del Portus Ilicitanus y no el de Calpe, la propia Villajoyosa u otros enclaves secundarios costeros. Más extraño todavía cuando habría que suponer que lo cita con un nombre alternativo o más antiguo (Allon) y no por el de puerto de Ilici, y aún más cuando ambos términos aparecen simultáneamente en Claudio Ptolomeo. La identidad de Allon con Santa Pola nos parece, por tanto, muy forzada. Creemos que es más sencillo y acorde con la lógica territorial romana que Mela cite -y por su orden correcto- las ciudades costeras del golfo de Ilici y sólo a ellas: Allon, Lucentum, Ilici, cada una lugar central de un territorio que corresponde, como es habitual, con una o más comarcas naturales. Santa Pola, el Portus Ilicitanus, es un enclave semiurbano perteneciente a Ilici, como su propio nombre indica: está en su territorium, y depende de la colonia. No es una ciudad distinta de Ilici -por muy pujante que fuera el enclave costero ubicado bajo Santa Pola en la primera mitad del s. I d.C.-, sino su puerto.

Igualmente resultaría muy extraño que la ciudad ibérica y romana de Villajoyosa, a la vista de la abundante epigrafía, de la entidad de su poblamiento y de sus monumentos y obras de ingeniería (Torre de Sant Josep, monumento de l'Almiserà, depósito hidráulico de Torres, termas de Jovada, villa monumental de Xauxelles, almacenes portuarios, calzadas, santuario, termas monumentales de la calle Canalejas, macellum, el templo y la curia pertenecientes a un centro urbano que cabe deducir del duunvir y flamen mencionado en una inscripción, etc.), resultaría muy extraño, decimos, que las fuentes clásicas, en una especie de ilógica damnatio memoriae, omitiesen un enclave así, incluso que no apareciera en ellas reiteradamente, más todavía cuando se encuentra en la costa (la principal vía de comunicación de la época).

La reiterada mención de Alonís y de Allon en las fuentes es conforme a estas expectativas. Como hemos expresado gráficamente en otro lugar, identificar estos topónimos con Villajoyosa permite unir el nombre reiterado sin ciudad y la ciudad privilegiada sin nombre. La interpretación de los itinerarios suele resultar conflictiva, por los errores que se derivaron del uso de fuentes escritas (indirectas) más que de una observación directa del paisaje por parte de sus autores. Es un terreno en el que conviene moverse con cautela. No obstante, las recientes relecturas de Alternum y de Celeris y sus variantes nos dibujan una ruta costera alternativa a la vía principal que baja por el Vinalopó hacia Ilici, y puede explicar las aparentes incorreciones del orden de las diferentes ciudades de la provincia de Alicante en las fuentes.

No obstante, hemos de manifestar que la interpretación de Corell parece algo forzada, por cuanto el redactor del Ravennate (y el de la Guidonis Geographica) no realizó una hipertraducción más que de una de las dos hipotéticas menciones de Allon -la primera- a Asterum y Alterum respectivamente. Si dejamos Asterum/Alternum/Alterum como una indicación de bivium, la cuestió podría quedar en un ramal Sucro $>$ Dianium, y una continuación de la calzada principal Sucro>Saetabis $>$ Turres $>$ Ad Ello $>$ Ilici, con un atajo -celere (iter), literalmente, (camino) 'rápido'-, con origen entre estos dos últimos lugares, hacia Lucentum que sube hasta Allon, como propone Corell. No es de extrañar que la vía costera carretera entrara a la Marina Baixa por el sur, desde Lucentum, y no por el norte, 
desde Dianium, dada la fuerte dificultad del barranc del Mascarat, entre Altea y Calpe, como veremos después. De cualquier modo, en este modelo se nos queda descolocada Dianium en el libro IV del Ravennate, como reconoce Corell (1999, 178), pero su ubicación en Ravennate V y en la Guidonis Geographica inmediatamente al sur de Sucro hace sospechar a este autor -fundadamente, en nuestra opinión- que su posición en el libro IV es errónea.

Géza Alföldy (2003, 49 y notas 86 a 90), por su parte, ha manifestado también recientemente su opinión de que Allon se encuentra al sur de Lucentum y que Mela se equivoca al localizarlo al norte de la misma, y no acepta la identificación de Alternum y sus variantes con Allon, propuesta por Corell.

El yacimiento de Picola, para el que Moret (2000) propone su identificación con Allon (y, con dudas, con Alonís), se mantuvo ocupado desde 450/430 a 350/330, sin una continuidad arqueológica aparente hasta el gran desarrollo portuario augusteo, lo que supone un desfase nada menos que de tres siglos (vid. Márquez, 1999, 103-105; cf. Márquez y Molina, 2001; vid. Moret, 2000, 250). Precisamente en este período, los s. III a I a.C., el enclave de Villajoyosa experimenta una época de esplendor, y no podemos olvidar que se corresponde con la fechas en las que escriben tanto Artemidoro como Estrabón (aún teniendo en cuenta su uso de fuentes anteriores).

Recientemente Antonio García Menárguez $(2001,547)$ ha publicado un artículo en el que concluye que «es posible plantearse como hipótesis lo siguiente: si el topónimo Alone significa etimológicamente «plaza de sal» $\mathrm{y}$, como tal, conceptualmente, se le reconocía en el mundo antiguo como "un mercado de sal», en este caso Guardamar del Segura y su territorio costero pueden identificarse con Alone». No obstante, la mayor parte de los especialistas del País Valenciano con los que he tenido oportunidad de departir en los últimos años -como el propio A. García Menárguez- se muestran convencidos de que Allon se encuentra en Villajoyosa. La frecuencia, entidad y antigüedad de los hallazgos que se están produciendo en su término municipal nos da una imagen cada vez más relevante de este núcleo en la Protohistoria y la Arqueología clásica del levante peninsular. La identificación de Allon con Villajoyosa es, actualmente, una opinión casi generalizada en la investigación valenciana.

En fin, F. Benoit $(1965,105)$ propuso la localización de Alonís en la Provenza, y P. Moret
$(2000,253)$ la diferencia de la Alonai de Ptolomeo y de $A l l o n^{27}$, considerando que las dos últimas sí hacen referencia al mismo enclave (que sitúa, como hemos visto, en Santa Pola), y afirmando, sobre la base de los argumentos de Benoit, que «rien ne permet d'affirmer que l'île d'Alônis se trouvait sur la côte espagnole», dando por sentado -tras un exhaustivo análisis filológico- que «Alônis était, à l'époque hellénistique, une île habitée», lo que no parece confirmarse en Tabarca ni en la isla de Benidorm, las dos candidatas de la costa alicantina. Moret se separa, así, de la hipótesis tradicional, generalmente aceptada, que suponía que Alonís era una ciudad frente a la cual había una isla del mismo nombre (vid. Moret, 2000, 246 y nota 45).

El nombre actual de Villajoyosa (La Vila Joiosa, en catalán occidental) no nos puede ayudar, puesto que, como hemos señalado más arriba, es de origen romance, un nombre nuevo para una ciudad nueva, de finales del s. XIII. Sin embargo, muchas veces nos hemos preguntado si no se habría fosilizado el nombre de la ciudad antigua en algún topónimo que hubiese resistido el paso del tiempo en los últimos trece siglos, después de la conquista árabe, como lo ha hecho Torres. Incluso nos hemos llegado a plantear si Torres no era el nombre del asentamiento de la desembocadura de este río, sea cual sea su entidad. La constatación de que el poblamiento islámico de Villajoyosa se encuentra al interior, en la partida de l'Almiserà, a $3 \mathrm{Km}$. del yacimiento Torres I y por tanto de la playa, pero junto al cauce del río de este mismo nombre, nos ha llevado a proponer (Espinosa, 2006) que esas alquerías son herederas del poblamiento romano de la misma zona interior (Turris o Turres, un topónimo frecuentísimo en el ámbito romano), pero no podemos descartar un fenómeno a la inversa: que el vicus del que procedería el topónimo Torres esté situado en Torres I, en la desembocadura, y que en época islámica se retrotrajera al interior, como lo hace el poblamiento, sirviendo el propio río Torres como vehículo transmisor del topónimo.

En el estado actual de la investigación, los restos monumentales bajo la actual ciudad de Villajoyosa confirman que la ciudad se encuentra allí, y que Torres era un vicus con su nombre propio, ubicado bien en la desembocadura (yacimiento de Torres I), bien al interior. El río (en realidad un barranco con cinco meses de estiaje;

27. Sin descartar absolutamente que las tres pudieran identificarse (Moret, 2000, 250). 
vid. Espinosa, 2006) ha mantenido el topónimo hasta hoy, y la inscripción que Corell (supra) atribuye a Villajoyosa, encastada en algún muro de la iglesia de la Asunción y hoy cubierta de enlucido, en la que se lee Turris Genio, muy bien podía hacer alusión a la deidad protectora de este vicus. Tampoco podemos descartar absolutamente que no haga referencia al nombre de la propia ciudad, aunque no lo consideramos probable por todos los motivos que esgrimimos en este artículo.

El hecho de que el río de Torres haya fosilizado, con toda probabilidad, un topónimo romano (a través incluso del poblamiento islámico, que lo adopta), nos anima a analizar el nombre de uno de los dos ríos más destacados de la comarca, el que desemboca en Villajoyosa, junto a la antigua ciudad ibérica y el posterior núcleo romano, hoy conocido como Amadorio. Importante aguada junto al puerto y fondeadero histórico, este río es clave para comprender la relevancia recurrente del asentamiento de su desembocadura, con hitos más recientes como la fundación aragonesa de Vila Joiosa en 1300 en el cerro del casco antiguo, despoblado desde hacía siglos, o la segunda matrícula naval de España que tuvo este puerto hacia 1860 . El nombre de la ciudad antigua puede haberse desvanecido con la realidad física de su poblamiento en la Alta Edad Media (testimoniada por la arqueología) pero, en el caso de que el río hubiera portado su mismo nombre (como sucede en Sucro o Torres) podemos albergar la esperanza de conservar en él la misma raíz que el de la ciudad antigua, porque los ríos no se desvanecen del paisaje: perduran, y con ellos con frecuencia su nombre, al extenderse su uso a lo largo de kilómetros, hacia el interior, no sólo por la población litoral en la que desemboca sino también por las del hinterland por las que discurre.

Es un hecho conocido que el nombre de Amadorio es reciente (s. XIX). Francesc Xavier Llorca Ibi $(2006,203)$ cree que es posible que haya que atribuirlo a un error en el diccionario de Pascual Madoz (1845). Advierte Llorca que éste río «és l'únic del qual no trobem referències nominals en l'abundant història cartogràfica del Regne de València». Es decir: se ha perdido en la memoria colectiva su nombre original, a favor de «río de la Vila» o "Amadorio». Únicamente se encuentra una referencia al río de Tolons en un mapa parisino de 1838, realizado por $\mathrm{A}$. $\mathrm{H}$. Dufour, y anteriormente en el de Tomás López de 1788, en el que se lee "Puerto de Tolons» (Llorca Ibi, 2006, 203-204), lo que en el idioma original (catalán occidental o valenciano) debe ser Port de Tolons.

No se ha conservado en el término municipal de Villajoyosa ningún topónimo asimilable a éste (cf. Esquerdo y Sais, 1999), pero sí en el término colindante de Relleu, que en la antigüedad pertenecía sin duda al territorium de la ciudad romana de Villajoyosa. Cerca de aquella población, en la orilla derecha del río Amadorio (a $12 \mathrm{Km}$ de su desembocadura), arranca un barranco que vierte sus aguas en él, el barranc de Bortolons, nombre igualmente de un camino, caserío y partida rural de las inmediaciones. Es posible que este topónimo sea una contracción de Port Tolons, y esté fosilizando el nombre antiguo del río.

En el coloquio que siguió a la ponencia de F. X. Llorca (2006) en las II Jornades de Patrimoni de la Marina Baixa planteamos, en relación con este topónimo que, si efectivamente el nombre más antiguo que conocemos del río es de Port de Tolons, de Port Tolons o, simplemente, el de Tolons, es muy probable que haga referencia a su nombre clásico, como sucede en el caso de Torres. En este caso, río de Port Tolons o de Tolons puede derivar de Portus Allonensis o Portus Allonis (el río desembocaba junto al puerto ibérico y romano, y le servía, como hemos dicho más arriba, de aguada), a través de una forma del tipo Portalons.

\section{LA VÍA COSTERA ENTRE DIANIUM Y LUCENTUM}

Otra cuestión es el hecho de que el Ravennate incluya Allon -independientemente del orden en el que lo hace, sea éste correcto (como opina Corell) o no-. Ello supone que a ésta población había de llegar una vía, ya que se trata de una guía de caminos, lo que choca frontalmente con la total incomunicación de la comarca propuesta inicialmente por E. Llobregat (1983, 220), y ampliamente aceptada por la investigación posterior (vid. Rosselló, 1992, 633). Se trata de una concepción en nuestra opinión desacertada: existen pruebas de la existencia de una vía secundaria, un ramal de la Via Augusta, que enlazaba Dianium con Lucentum, permitiendo la circulación puramente costera entre Valentia y Carthago Nova, como ya argumentamos detalladamente en nuestra Tesis doctoral (Espinosa, 1996 y 1998b, 104). Anteriormente se habían manifestado también a favor de esta opción Sillières (1990, 344-350), Reynolds (1993, 7-8, nota 4) o Arasa y Rosselló (1995, 78-79, 97, 119-120), en- 
tre otros. Corell $(1999,178$, nota 192) lo acepta igualmente, y G. Morote interpreta un texto de Plinio en Viejo (Naturalis Historia, III, 76) ${ }^{28}$ como prueba de la existencia de este camino directo entre Dianium y Carthago Nova, y propone un trazado desde Sucro hasta conectar con la vía principal al sur de Lucentum, pasando por la costa de las comarcas de la Safor y las Marinas Alta y Baixa.

Según la concepción de Llobregat, la sierra de Bèrnia, al $\mathrm{N}$; y al sur el paisaje quebrado de la "frontera-desierto» (en palabras de este mismo autor), formado por barrancos y lomas chatas, que ocupa el paisaje costero entre $\mathrm{Vi}$ llajoyosa y El Campello (en el que se encuentra la dificultad principal del cauce del riu d'Aigües) suponían barreras infranqueables que limitaban la comunicación exterior de la comarca de la Marina Baixa a la puramente marítima. Hay algo de cierto en ello, en el sentido de que la comarca parece haber estado siempre volcada al mar, debido precisamente a estos obstáculos, pero en modo alguno son infranqueables, como veremos.

La propia Via Augusta se desviaba al interior para evitar este tramo costero -es decir, las montañas que rodean la Marina Baixa y caen perpendicularmente a la costa, dificultando el paso a las comarcas vecinas- (cf. Roldán, 1973; Morote, 1979b; Llobregat, 1983; Abad Casal, 1985a y Rosselló Verger, 1992). A Dianium tan sólo llegaba un ramal, el mismo que debió continuar hacia el sur, para alcanzar Lucentum (cf. Espinosa, 1996).

Suscribimos plenamente la siguiente afirmación de A. Rodríguez Colmenero (1985, 401402): «lo normal en los trazados romanos de vías, sean éstas de la red oficial o promovidas por los municipios, es que se prolonguen hacia ciudades próximas o núcleos poblacionales de cierta importancia, de manera que ninguna ciudad, incluso marítima, constituye fondo de saco alguno para cualquier tipo de vía terrestre, salvo las que discurren perpendiculares a la costa. Por otra parte, la existencia en esa dirección de centros litorales tan importantes como Villajoyosa, el Tossal, Lucentum y Santa Pola, así como la misma importancia económica del litoral levantino en época antigua, persuaden en el sentido de que dicho camino, principal o secundario, tuvo que

28. «...absunt ab Dianio DCC stadia, totidem Dianium per continentem a Carthagine Nova...». existir» ${ }^{29}$. Hay que tener en cuenta que en los itinerarios no tiene por qué estar reflejada la totalidad de la red viaria, aunque en nuestro caso, si es correcta la hipótesis de la identificación de Allon con la ciudad de Villajoyosa, sí encontraríamos referencias a la misma en varias fuentes ${ }^{30}$.

En el repertorio de caminos de Juan Villuga (1546-1950) se recogen ambas rutas. Así pues, antes del gran desarrollo de las comunicaciones por tierra en el s. XVIII, la Marina Baixa estaba regularmente conectada con la Marina Alta y con l'Alacantí por la vía costera (cf. Piqueras y Sanchís, 1992). Este itinerario da como hitos Denia, Jávea, Teulada, Calpe, Altea, 'Bien Duermo' (=Benidorm), Villajoyosa y Alicante (vid. Arasa y Rosselló, 1995, 59).

Desde Villajoyosa, el camino pudo seguir por la costa, en dirección a Calpe, donde existe un importante poblamiento romano, para el que en su día propusimos su identificación con un vicus asociado a una importante villa a mare, los Baños de la Reina, a medio camino entre los municipios de Villajoyosa y Dianium: 20 millas romanas lo separaban de la primera y 24 de la segunda. Estos valores se ajustan a una constante (modica interualla) detectada en general en el número de millas que separan las mansiones ${ }^{31}$, que se sitúan precisamente entre esos valores, 20 y 24 millas $^{32}$.

Para llegar a Calpe hubo de franquear las estribaciones de la sierra de Bernia, entre ésta y el Morro de Toix, por el punto conocido como "collado de Calpe», mencionado con frecuencia

29. E. Llobregat (1983, 236-237) hizo un repaso de los trazados de la Vía Augusta propuestos por autores anteriores, en los que se recogían, por lo general, dos posibilidades: la existencia de una vía litoral o la de dos rutas, ésta y la interior. El artículo de Llobregat inclina la balanza decisivamente en favor del trazado interior, identificándolo con la Via Augusta -de lo que no hay la menor duda actualmente-, al tiempo que su hipótesis de la imposibilidad física de la continuidad de un ramal litoral por la Marina Baixa caló profundamente en la investigación posterior, que la aceptó plenamente.

30. M. Tarradell $(1988,157)$ da también por supuesta esta vía costera, basándose en similares razones. A la misma conclusión llega F. Brotons (1996) en su reciente reinterpretación del Ravennate.

31. Las mutationes se situaban cada menos distancia, inferior a 9 millas según F. Arasa y V. M. Rosselló $(1995,82)$.

32. No obstante, en el País Valenciano los márgenes inferior y superior constatados son son $15-16$ millas $(=22-23,5$ $\mathrm{Km}$ ) y 27 millas $(=40 \mathrm{Km}$ ) (Arasa y Rosselló, 1995, 81-82 y 99 ss.). Para el caso extremeño vid. Gorges, 1990, 71. 
en documentos de época moderna ${ }^{33}$. Este lugar estuvo controlado en época ibérica por el poblado de El Castellet (Calpe) -donde se erigió posteriormente un castillo islámico $y$, en época moderna, una casa de carabineros-. Su mera existencia invalida la hipótesis de la incomunicación comarcal hacia el $\mathrm{N}$ por la línea de costa ${ }^{34}$. Constituía un paso incómodo, con fuertes pendientes, como quedaba reflejado en el Ytinerario de Catarroja a Alicante por Alcoy y de Alicante al mismo punto de partida por el litoral ejecutada por los capitanes del Cuerpo de E. M. del Ejército Don Nicolás Lloret y Reimer y Don Manuel Cortés y Morales, datado en 1853 (Pastor, 1985): en este documento se lo califica de «mal paso conocido en el país», y de «subida penosa» ${ }^{35}$. A la dificultad del propio collado hay que añadir los cauces de algunos barrancos que preceden a la subida por el lado de Altea ${ }^{36}$.

No obstante lo dicho, el collado de Calpe es la opción menos mala para franquear la Sierra de Bernia y comunicar por el litoral las comarcas de la Marina Baixa y la Marina Alta, aunque el tránsito de un carro debía de ser difícil. La propia Sierra de Bernia tiene otros pasos más retirados al interior, muy difíciles (pas dels Bandolers, el Portitxol, coll de Fachuch). Para dirigirse de Ca-

33. Vid. Pastor 1985; Pastor y Campón, 1986, 14, 25-30 y 4041; y Madoz, 1848, 195, 197 y 201. Podemos destacar el exhaustivo informe que, sobre la Sierra de Bernia, escribió Giovanni Battista Antonelli para Felipe II en 1561.

34. Al N de la serra de Bèrnia, A. Ronda $(1990,166)$ ha identificado un camino romano que partiría de la vía litoral hacia el interior, para adentrarse en término de Benissa.

35. He aquí un extracto del texto: «pasado el barranco de Galera, que no lleva corriente más que en épocas lluviosas, así como los otros barrancos que hay antes, se separa el camino de la costa e internándose en la cordillera que forma el cabo de Toix, ramificación del monte Serrella y sierra de Aitana, empiezan las subidas y bajadas que se aumentan en puntos notablemente; y conforme se avanza en la marcha para pasar el barranco y collado de Calpe, puede decirse que el camino se convierte en un desfiladero completo, tanto por el gran declive de las estériles montañas que se elevan a la izquierda, como por los muchos escarpados de piedras que estas tienen, mayormente en sus cumbres, y que imposibilitan el franqueo sin largos rodeos. El paso por este camino será muy pesado para las tropas por las muchas cuestas y la naturaleza del piso pedregoso en especial después del trozo de camino carretero construido y en la mala subida del collado. En el descenso a la parte NE desde la cima del collado se encuentran semejantes accidentes, reuniendo el camino las mismas circunstancias que por el otro lado y siendo sucesivamente más suaves las pendientes (...) hasta Calpe» (tomado de Pastor, 1985).

36. El trayecto total entre Calpe y Altea se cifra en $2 \mathrm{~h}$. en este documento. llosa a Jalón (ya en la Marina Alta) se ahorraba, no obstante, dos horas por el Portitxol, a pesar de su dificultad, dado que el camino costero suponía un importante rodeo. Sin embargo, el tráfico de personas y de mercancías debía discurrir preferentemente por este último en la época romana, a juzgar por la viabilidad de la llanura litoral y por la importancia del poblamiento asociado -así el asentamiento de La Pila, en Altea, que identificamos con un vicus (Espinosa, 1996; vid. Martínez García, 2005, 39), o el de Garganes, donde se conocen unos almacenes portuarios asociados a la desembocadura del río Algar, excavados por Gabriel Segura (Espinosa, Sáez y Castillo, 2006, 38-39 y fig. 28).

Desde Calpe, el camino continuaría hacia Denia por el trazado propuesto por F. Arasa y V. M. Rosselló (1995, 120), en el que se incluyen restos de un puente descubierto junto al río Gorgos.

Desde el collado de Calpe hacia el sur, el camino no tendría mayores dificultades -salvo los cauces de algunos barrancos- para alcanzar Altea, desde donde continuaría ceñido a la costa, pasaría junto a los yacimientos de Cap Blanc, l'Albir y el Ventorrillo, y aprovecharía la suave topografía del sinclinal de la Marina para dirigirse a las inmediaciones de Benidorm, por el camí vell del Plà de la Serra. Desde Benidorm el camino discurría al sur por la propia playa de Poniente, aunque sabemos que la arena suponía una cierta incomodidad.

Por el sur, el tránsito hacia el territorium de Lucentum desde Villajoyosa no es imposible por la costa, aunque sí bastante accidentado, por lo quebrado del terreno: la dureza del tramo puede explicar que la primera mutatio probable se encontrara a una distancia algo escasa del núcleo de Villajoyosa, 7,5 Km. Se trata del yacimiento altoimperial de la desembocadura del barranco del Carrichal, situado junto a una antigua posta en ruinas, en el camino costero de Alicante. Se encuentra rodeada de terrenos casi despoblados, secos e inhóspitos.

El río o barranco de Aguas, de cauce normalmente seco, es, quizá, la única dificultad más o menos seria para un carro, aunque en modo alguno insalvable, como demuestra el trazado del camino del s. XVI, que, en líneas generales, debe coincidir con el romano.

Un nuevo argumento a favor de este ramal litoral ha venido de la mano del hallazgo de tramos de calzada, empedrados hacia comienzos del s. I a. C., que fosilizan vías más antiguas (al menos del s. VI a. C., a juzgar por las tumbas que lo flanquean en las necrópolis de Casetes y 
de Poble Nou). Una de estas calzadas (Espinosa, Ruiz y Marcos, 1995; Espinosa, Ruiz, Marcos y Peña, en prensa) sigue la calle Pianista Gonzalo Soriano hacia la Creu de Pedra, a $3 \mathrm{Km}$ al interior, y desde allí se dirigiría hacia Alcoy: con ella enlazaba un tramo excavado recientemente en el yacimiento Jovada II, y que se dirige claramente en paralelo a la costa, en dirección Este. Probablemente nos encontramos ante el arranque del camino antiguo que conectaba con la Marina Alta (Fig. 8).

La segunda calzada, con tramos excavados que nos permiten seguirla a lo largo de $1 \mathrm{Km}$ de longitud, se dirigía hacia Alicante por la costa flanqueada a ambos lados por la necrópolis de Poble Nou. En ambos casos se trata de firmes de cantos, de $4 \mathrm{~m}$ de ancho, con muretes a uno o a los dos lados en parte de su recorrido.

En fin, hemos traído aquí y revisado la argumentación que realizamos hace diez años en nuestra Tesis doctoral sobre la identificación de Alonís y Allon como el mismo enclave y que éste se corresponde con la ciudad ibérica y romana de Villajoyosa, analizando las recientes publicaciones de otros autores en las que se ha abordado esta cuestión y poniéndolo todo a la luz de las recientes evidencias arqueológicas. Hemos insistido en el papel de este núcleo como lugar central de la comarca de la Marina Baixa en las épocas ibérica y romana, en su relevancia en el contexto de las costas valencianas, y en que la equivalencia de ambos topónimos con Villajoyosa puede ser en general acorde con los itinerarios, y permite casar, como hemos expresado gráficamente, «la ciudad privilegiada sin nombre y el nombre reiterado sin ciudad».

Sin embargo, y aunque lógicamente como arqueólogo municipal de Villajoyosa soy parte interesada y -como cualquiera-corro el riesgo de querer «arrimar el ascua a mi sardina», me veo en la obligación de pedir un poco de paciencia.

No faltan ejemplos (incluso muy cercanos, como en el caso de Benalúa y Lucentum) de errores de adscripción que se han fosilizado después en la bibliografía cuando parecían incontestables, provocando confusión en medios científicos. A pesar de que estoy personalmente convencido de que Villajoyosa alberga la Alonís ibérica (sea cual sea su forma indígena) y su heredera romana, Allon, y de que con insistencia me llegan opiniones de numerosos colegas que manifiestan su acuerdo con esta hipótesis, creo conveniente que nos mantengamos en el terreno de eso, de la hipótesis, por muy claras que parezcan las pruebas a su favor. No hay prisa por confirmar la adscripción, por consagrarla. De hecho, los argumentos esgrimidos por P. Moret respecto a Alonís y Alonai son fruto de un minucioso análisis de los textos y merecen ser tenidos en cuenta.

Llegará un día -espero-, seguramente el menos pensado, en el que aparecerá una prueba directa, la única que autoriza una reducción toponímica definitiva. La impaciencia, ya se sabe, no es buena compañera. Mientras tanto, me parece aconsejable acompañar un simple signo de interrogación al topónimo Allon cada vez que se emplee en relación con un yacimiento arqueológico.

Las investigaciones se están desarrollando, precisamente, en Villajoyosa sobre los puntos clave para dilucidar el origen de la ciudad antigua: el centro urbano (donde está saliendo a la luz un conjunto monumental) y la partida de Torres (donde ya habrán comenzado los sondeos en extensión en toda la zona cuando este artículo vea la luz). Si se ha conservado una inscripción que contenga el nombre del municipio romano, estamos muy cerca.

\author{
Dr. Antonio Espinosa Ruiz \\ Museo Municipal de la Vila Joiosa \\ $\mathrm{C} /$. Barranquet, 4 \\ 03570 La Vila Joiosa \\ museo@villajoyosa.com \\ antonio.espinosa@ua.es
}

\section{BIBLIOGRAFÍA}

ABAD CASAL, L., 1984: «La Romanización», en Alcoy, Prehistoria y Antigüedad, Alcoy.

ABAD CASAL, L., 1990: Llobregat Conesa, E. A. y Abad Casal, L. (coord.): Historia de la ciudad de Alicante, tomo I (Edad Antigua), Alicante.

ABAD CASAL, L. y ABASCAL PALAZÓN, J. M., 1991: Textos para la historia de Alicante. Edad Antigua, Alicante.

ABAD CASAL, L. y BENDALA GALÁN, M., 1985: «Los sepulcros turriformes de Daimuz y Villajoyosa: dos monumentos romanos olvidados», Lucentum, IV, 147 ss.

ABASCAL PALAZÓN, J. M., 1996: «Derecho latino y municipalización en levante y Cataluña», en ORTIZ DE URBINA, E. y SANTOS, J. (Eds.): Teoría y práctica del ordenamiento municipal de Hispania, Actas del Symposium de Vitoria-Gasteiz (noviembre de 1993) (Revisiones de Historia Antigua II), 255-283.

ABASCAL PALAZÓN, J. M. y ESPINOSA RUIZ, U., 1989: La ciudad hispano-romana. Privilegio y poder, Logroño.

ALFÖLDY, G., 2003: «Administración, urbanización, instituciones, vida pública y orden social», en Abascal, J. M. y Abad, L. (coord.): Las ciudades y los campos de Alicante en la época romana, Canelobre 48, 35-58.

ARASA, F. y ROSSELLÓ, V. M., 1995: Les víes romanes del territori valencià, València.

BARRIER, P., MONTENAT, CH. y ROUILLARD, P., 2004: «Paysage protohistorique de l'embouchure du Segura: approche paléogeographique et environnementale», en 
De Maria, L. y Turchetti, R. (Eds.): Evolución paleoambiental de los puertos y fondeaderos antiguos en el Mediterráneo occidental, I Seminario ANSER (Alicante, noviembre de 2003), 231-246, Roma.

BENOIT, F., 1965: Recherches sur l'hellénisation du Midi de la Gaule, Aix-en-Provence.

BEUTER, P. A., 1538: Primera part de la Història de València que tracta de les Antiquitats de Espanya y fundació de València, ab tot lo discurs fins al temps que lo ínclit rey don Jaume la conquistà, Valencia.

BOX AMORÓS, M., 1987: Humedales y áreas lacustres de la provincia de Alicante, Alicante.

BROTONS YAGUE, F., 1996: «El Anónimo de Ravenna y la trama viaria del Levante Español. Ensayo de interpretación y restitución», en Actas del XXIII Congreso Nacional de Arqueología (Elche, 1995), Elche.

CABANES, M. D. et alii, 1981: Documentos y datos para un estudio toponímico de la Región Valenciana, València.

CASTILLO, R., ESPINOSA, A. y SÁEZ, F., 1998: «Dos fondeaderos romanos en la Marina Baixa (Alacant): la platja de la Vila (La Vila Joiosa) y l'Olla (Altea), en Pérez Ballester, J. y Pascual Berlanga, G. (Ed.): III Jornadas de Arqueología Subacuática, Actas de las Jornadas (Valencia, 1997), 115-130. Valencia.

CEBRIÁN FERNÁNDEZ, R., 2000: Titulum fecit. La producción epigráfica romana en las tierras valencianas (Biblioteca Archaeologica Hispana 7), Madrid.

CORELL, J., 1999: Inscripcions romanes d'llici, Lucentum, Allon, Dianium i els seus territoris, Nau Llibres, Valencia.

DIAGO, F., 1613: Anales del Reyno de Valencia, Valencia.

DIDIERJEAN, F., NEY, C. y PAILLET, J. L., 1986: Bélo III. Le macellum, Madrid.

ESCOLANO, G., 1610 (1879): Décadas de la historia de la insigne y coronada ciudad y reino de Valencia, Valencia.

ESPINOSA RUIZ, A., 1995a: La investigació arqueològica a la Vila Joiosa, Villajoyosa.

ESPINOSA RUIZ, A., 1996b: «Dos yacimientos romanos del casco urbano de Villajoyosa, a partir de los fondos del Museo local. Consideraciones sobre la ubicación del Municipium y su relación con el poblamiento ibérico», en Actas del XXIII Congreso Nacional de Arqueología, (Elx, 1995), vol. II, 187-194.

ESPINOSA RUIZ, A., 1998a: «Història de les investigacions sobre Arqueología romana en la comarca de la Marina Baixa», Sarriá 0 (Revista d'investigació i assaig de la comarca de la Marina Baixa), 1998.

ESPINOSA RUIZ, A., 1998b: "Sobre el nom de la ciutat romana de la Vila Joiosa», Sarrià 1 (Revista d'investigació i assaig de la comarca de la Marina Baixa), 99-112.

ESPINOSA RUIZ, A., 1999: «El proceso de romanización de la comarca de la Marina Baixa (Alicante)», I/ Congreso de Arqueología Peninsular (Zamora, Septiembre de 1996), vol. IV, 75-82, Alcalá de Henares.

ESPINOSA RUIZ, A., 1991: «Los mosaicos de la villa bajoimperial de Torre-la Cruz (Villajoyosa, Alicante)», CuadPrehistA, 17, 219-253.

ESPINOSA RUIZ, A., 1996a: Arqueología romana de la comarca de la Marina Baixa (Alicante), tesis doctoral inédita, Departamento de Prehistoria y Arqueología de la Universidad Autónoma de Madrid, 6 de junio de 1996.

ESPINOSA RUIZ, A., RUIZ ALCALDE, D. y MARCOS GONZÁLEZ, A., 2005: «Nuevas aportaciones al conocimiento de la Vila Joiosa en época ibérica», en ABAD, L., SALA, F. y GRAU, I. (Eds.): La Contestania ibérica, treinta años después, 179-198, Alicante.

ESPINOSA RUIZ, A., RUIZ ALCALDE, D., MARCOS GONZÁLEZ, A. y PEÑA, P. (en prensa): «Nuevos testimonios romano-republicanos en Villajoyosa: un probable campamento militar del s. I a.C.», en Iberia e Italia: modelos romanos de integración territorial, Actas del IV Congreso Hispano-Italiano (Murcia, 2006).

ESPINOSA RUIZ, A., SÁEZ LARA, F. y CASTILLO BELINCHÓN, R., 2006: Puertos y navegación en las costas meridionales valencianas (s. I-X d. C.), British Archaeological Reports (B.A.R.), International Series 1475, Oxford.

ESQUERDO VAELLO, M. L. y SAIS DEVESA, M., 1999: Aproximació a la toponímia vilera, Villajoyosa.

FIGUERAS PACHECO, F., 1913: Geografía General del Reino de Valencia. Provincia de Alicante, Barcelona.

GARCÍA GANDÍA, J. R., 2005: La necrópolis orientalizante de Les Casetes. Ajuares y estructuras funerarias, en Abad, L., Sala, F. y Grau, I. (Eds.): La Contestania ibérica, treinta años después, 345-356, Alicante.

GARCÍA GANDÍA, J. R., 2003: «La tumba 17 de la necrópolis de Les Casetes (La Vila Joiosa, Alicante)», Saguntum 35, 219-227.

GARCÍA MONTALBÁN, A., 1984: Epigrafía latina de la provincia de Alicante, Memoria de Licenciatura inédita, Universidad de Alicante.

GOZÁLBEZ, V., 1974: «La centuriatio de llici», Estudios sobre centuriaciones romanas en España, 101-113, Madrid.

GRAU MIRA, I., 2002: La organización del territorio en el área central de la Contestania Ibérica, Alicante.

GUTIÉRREZ LLORET, S., 1999: «Cuando el Portus dejó de ser puerto: el territorio ilicitano en la Alta Edad Media (s. VI-X), Nuestra Historia, I Congreso de Historia Local (Santa Pola, 1997), 7-25. Alicante.

HOLDER, A., 1894-1916: Alt-Celtischer Sprachschatz, Leipzig.

LE ROUX, P., 1990: «Les villes de statut municipal en Lusitanie romaine», en Les villes de Lusitanie romaine, Table ronde de Talence (1988), Paris.

LLOBREGAT CONESA, E. A., 1969: «Hacia una desmitificación de la Historia Antigua de Alicante. Nuevas perspectivas sobre algunos problemas», RAlicante I, 35-44.

LLOBREGAT CONESA, E. A., 1974: «Avance de una prospección del catastro romano en la provincia de Alicante», en Rosselló Verger, V. M. et alii: Estudios sobre centuriaciones romanas en España, 91-100, Madrid.

LLOBREGAT CONESA, E. A., 1983: «Relectura del Ravennate: dos calzadas, una mansión inexistente y otros datos de la geografía antigua del País Valenciano», Lucentum II, 225-242.

LLOBREGAT CONESA, E. A., 1984: «lberización», en Alcoy, Prehistoria y Antigüedad, 231-258. Alcoi.

LLORCA IBI, F. X., 2006: "Toponímia de la Marina Baixa», en Actes de les II Jornades de Patrimoni Natural i Cultural de la Marina Baixa: Patrimoni, Aigua i Clima a la Marina Baixa (La Vila Joiosa, diciembre de 2005), 199-206, Villajoyosa.

MARCOS GONZÁLEZ, A. y RUIZ ALCALDE, D., 2005: «Las necrópolis de Poble Nou y de Casetes (sector Creueta). Dos yacimientos ibéricos excepcionales de Villajoyosa», en García León, J. M. y Espinosa Ruiz, A. (Eds.): I Jornades sobre l'actualitat del patrimoni arqueològic $i$ etnogràfic a la Marina Baixa (Altea, diciembre de 2004), 73-80, Elche.

MÁRQUEZ VILLORA, J. C., 1999: El comercio romano en el Portus llicitanus. El abastecimiento exterior de productos alimentarios (siglos I a.C.-V d.C.), Alicante.

MÁRQUEZ VILLORA, J. C. y MOLINA VIDAL, J., 2001: EI comercio en el territorio de llici. Epigrafía, importación de alimentos y relación con los mercados mediterráneos, Alicante. 
MARTíN, G., 1968: «La supuesta colonia griega de Hemeroskopeion: estudio arqueológico de la zona de DeniaJávea», Papeles del Laboratorio de Arqueología de Valencia 3.

MARTÍNEZ GARCÍA, J. A., 2005: «Patrimonio arqueológico en Altea», en García León, J. M. y Espinosa Ruiz, A. (Eds.): I Jornades sobre l'actualitat del patrimoni arqueològic $i$ etnogràfic a la Marina Baixa (Altea, diciembre de 2004), 37-48, Elche.

McELDERRY, R.K., 1918: «Vespasian's Reconstruction of Spain», en JRS 8.

MESTRE SANCHÍS, A., 1981: Humanismo y crítica histórica en los ilustrados alicantinos, Alicante.

MEZQUÍRIZ, M. A., 1983: «Pompaelo, ciudad romana», Revista de Arqueología 30, 26-33.

MONTANER Y SIMÓN (Ed.), 1897: Diccionario Enciclopédico Hispano-Americano de Literatura, Ciencias y Artes, t. 22, Barcelona.

MONTENEGRO, A., 1975: «Problemas y nuevas perspectivas en el estudio de la España de Vespasiano», ArchEspA 54, 37-86.

MOREL, J. P., 1966: «Les Phocéens en Occident: certitudes et hypothèses», PP CVIII-CX, 378-420.

MORET, P., 2000: «Un nom pour des ruines», en Badie, A. et alii: Le site antique de La Picola à santa Pola, (Alicante, Espagne), 2001, cap. I, 239-254. París-Madrid.

MOROTE BARBERÁ, J. G., 2002: La Vía Augusta y otras calzadas en la Comunidad Valenciana, 2 vol. (Real Academia de Cultura Valenciana, Serie Arqueológica 19), Valencia.

MÜLLER, C., (1883-1901): Claudii Ptolemaei Geographia, vol.1-2, París.

OLCINA DOMÉNECH, M. A., 1990a: «El Tossal de Manises en época romana», en Llobregat Conesa, E. A. y Abad Casal, L. (coord.): Historia de la ciudad de Alicante, tomo I (Edad Antigua), 149-188. Alicante.

OLCINA DOMÉNECH, M. A., 1990b: «Partida de Torres. La Vila Joiosa», en Excavacions arqueològiques de salvament a la Comunitat Valenciana 1984-1988. II, Intervencions rurals, 91-93, València.

PASTOR FLUIXÀ, J., 1985: «Descripción del camino entre Altea y Calp en 1853», Calp 15, s./pág.

PENA, M. J. 1989: «Avieno y las costas de Cataluña y Levante I. Tyrichae, Typicaí, ¿ «la Tiria»?», Faventia 11/2, 9-21.

PÉREZ BURGOS, J. M., 1996: «La excavación arqueológica de urgencia Tabarca I (Isla de Nueva Tabarca, Alicante), Actas del XXIII Congreso Nacional de Arqueología (Elche, 1995), vol. II, 179-185.

PIQUERAS, J. y SANCHÍS, C., 1992: L'organització històrica del territori valencià, València.

POVEDA NAVARRO, A., 1991: «Transformación y romanización del hábitat ibérico contestano de las cuencas alta y media del Vinalopó (provincia de Alicante). Del final de la República al Alto Imperio», Alebus 1, 65-78.

PUERTA, C. y STYLOW, A. W., 1985: «Inscripciones romanas del sureste de la provincia de Córdoba», Gerión 3, $\mathrm{VI}, 331 \mathrm{ss}$

RABANAL ALONSO, M. A. y ABASCAL PALAZÓN, J. M., 1985: «Inscripciones romanas de la provincia de Alicante», Lucentum IV, 217-223.

RABANALALONSO, M. A., 1985: «El Alto Imperio», en AA.VV: Historia de la provincia de Alicante, 347-389. Murcia.

RE I = Realencyclopädie der classischen Altertumswissenschaft, vol. I, 1912, Munich.

REYNOLDS, P., 1993: Settlement and pottery in the Vinalopó Valley (Alicante, Spain). AD 400-700, British Archaeological Reports, International Series 588, Oxford.

RICHMOND, I.A., 1957: The Archaeology of the Roman Empire, Oxford.

ROLDÁN HERVÁS, J. M., 1973: Itineraria Hispana, Madrid.

RONDA FEMENIA, A., 1990: Arqueología de Benissa, Alacant.

ROSSELLÓ VERGER, V. M., 1992: «Les vies romanes al País Valencià. Il.lusions i certeses», Homenaje a E. Plà Ballester, Trabajos Varios del S.I.P. 89, 619-637, València.

ROUILLARD, P., 1991: Les grecs et la Péninsule Ibérique, Paris.

RUIZ ALCALDE, D., MARCOS GONZÁLEZ, A.; MORATALLA JÁVEGA, J. y ESPINOSA RUIZ, A., (en prensa): Excavaciones en la necrópolis de Poble Nou (I): el sector de la calle Dr. Fleming, Publicacions del Museu de la Vila, Sèrie Catàlegs i Memòries, Villajoyosa.

RUYT, C. DE, 1983: Macellum: marché alimentaire des romains, Louvain-la-Neuve.

SCHULTEN, A., 1955: Iberische Landeskunde, I. StrasbourgKehl.

SILLIĖRES, P., 1990: Les voies de communication de l'Hispanie méridionale, Paris.

TARRADELL, M., 1965: «Prehistòria i Antiguitat», Història del País Valencià I, 15-206, Barcelona.

TARRADELL, M., 1988: «Prehistòria i Antiguitat», en Tarradell, M. y Sanchis Guarner, M.: Història del País Valencià, vol. I, Barcelona.

TOVAR, A., 1989: Iberische Landeskunde, III: Tarraconensis. Baden-Baden.

UROZ SÁEZ, J., 1981: Economía y sociedad en la Contestania ibérica, Alicante.

VALCÁRCEL, A., 1852 (1979): Inscripciones y Antigüedades del Reino de Valencia, Memorias de la Real Academia de la Historia, Madrid (Valencia).

VICIANA, R. M. DE, 1566: Chrónica de la ínclita y coronada ciudad de Valencia y su Reyno, Valencia.

WIEGELS, R., 1985: Die Tribunsinschriften des römischen Hispanien. Ein Katalog (Madrider Forschungen 13), Berlin. 